\title{
VALORACIÓN DEL PAISAJE Y DEL IMPACTO PAISAJISTICO DE LAS CONSTRUCCIONES EN EL PÁRAMO LEONÉS
}

\section{(EVALUATION OF LANDSCAPE AND LANDSCAPE IMPACT OF THE CONSTRUCTIONS IN PÁRAMO LEONÉS)}

Isabel Otero, Dr. Ingeniero de Montes; J.Carlos Novoa y Margarita Hernández, Ingenieros de Montes Dpto. de Construcción y Vías Rurales U.P.M.

ESPAÑA

\section{RESUMEN}

El articulo que se recoge en las páginas siguientes resume la metodología seguida.y las conclusiones obtenidas en un estudio sobre la valoración del paisaje y del impacto paisajístico de las construcciones realizado en el Páramo Leonés durante la primavera - verano de 1995.

La metodología seguida para la valoración del paisaje trata de integrar todos los aspectos que se pueden considerar para tal valoración (enfoque filosófico, psicológico y territorial), de modo que se contrasta y valida un método de valoración completo y aplicable a los paisajes españoles.

Para la estimación del impacto paisajistico de las construcciones se realiza una estimación de la adecuación de éstas al entorno tomando como base una tipología de las construcciones elaborada previamente.

El cruce de los valores de adecuación al entorno de cada construcción, con la valoración del paisaje en el que se sitúa proporciona finalmente el valor del impacto.

El trabajo desarrollado conduce a interesantes conclusiones relativas tanto a los valores propios del paisaje y las construcciones del Páramo Leonés como a las metodologías seguidas.

\section{SUMMARY}

This article contains a brief description of the methodology followed and the conclusions obtained in a study of the evaluation of landscape and landscape impact of the constructions carried out in the area of Páramo Leonés in the spring - summer period in 1995.

The methodology followed in the landscape evaluation tries to integrate all the aspects that can be taken into consideration when an evaluation of this kind is undertaken (phylosophical, psychological and territorial approach). Thus a complete evaluation method, applicable on Spanish landscapes, is verified and validated.

The estimation of the landscape impact of the constructions is conducted by estimating the adaptation of the constructions to the environment, taking as a basis a previously elaborated typology of the constructions.

The combination of the values of adaptation to the environment of each construction and the evaluation of the landscape in which the construction is situated gives the impact value.

The work carried out leads to interesting conclusions related to both values of the landscape itself and the constructions in the Páramo Leonés, as well as to the methodologies followed in the evaluations. 


\section{INTRODUCCIÓN}

El presente artículo resume un estudio ya realizado, cuyo objetivo básicofue abordar el problema de la valoración del paisaje y del impacto paisajístico de las construcciones agrarias. En el fondo se trata de dar valor o medir la belleza de un paisaje. Además de resumir los resultados del citado estudio, se detalla también, de forma breve, la metodología seguida, para que ésta pueda servir de guía para otros trabajos de valoración de paisaje y de impacto paisajístico

La valoración de la estética de un paisaje ha sido objeto de numerosos estudios durante los últimos años. Lo más destacable de estos estudios realizados es la falta de acuerdo en las conclusiones obtenidas, hecho éste motivado fundamentalmente por la disparidad de los puntos de vista desde los que se ha intentado abordar el problema de la valoración del paisaje.

Por tanto, según se evalúen las características del paisaje desde un punto de vista filosófico, psicológico, etc,..., los resultados obtenidos son diferentes. De estaforma, mientras que algunos autores intentan valorar el paisaje desde un punto de vista filosófico centrándose en cuestiones de definición (Dearden, 1987), midiendo la belleza del paisaje por su interrelación con el sujeto que lo observa; otros autores se basan en la posesión de atributos para la valoración del paisaje (Gómez Orea et al., 1976; Schauman, 1986; Litton, 1982; Zube et al., 1982; Kaplan, 1988), utilizando una serie de descriptores propios de cada paisaje (descriptores físicos, artísticos y psicológicos), que por separado proporcionan la valoración del paisaje en cuestión; un tercer grupo de autores aborda la valoración del paisaje desde el punto de vista psicológico, atendiendo al "impacto psicológico" que el paisaje produce en el observador (Bernáldez y Gallardo, 1989), centrándose más en la psicología que en el paisaje en sí; y, por último, se encuentran aquellos autores que emplean un enfoque basado en las características de los observadores (las características de los observadores que se utilizan son, principalmente: tipos de observadores, actitud hacia el paisaje, número de observadores de cada tipo y coste que supone para ellos el visitarlo o, en su caso, lo que estarían dispuestos a pagar para que no se deteriorara).

El método de valoración que se utilizó para la realización del trabajo que se describe en el presente artículo, es el propuesto por D. Ignacio Cañas Guerrero ("Integración de las construcciones agrarias en el paisaje: el color", tesis doctoral, E.T.S.I. Agrónomos de Madrid), tanto para la valoración del paisaje como para la valoración del impacto visual de las construcciones agrarias. Mediante dicho método, que se describe de forma breve más adelante, se pretende conjugar los distintos enfoques posibles en la valoración del paisaje, resultando así un método de valoración completo y aplicable a los paisajes españoles.

\section{DELIMITACIÓN DE LA ZONA DE ESTUDIO}

El área en la que se centra el presente estudio es la correspondiente al "Páramo Leonés", situada en el extremo Suroriental de la provincia de León. Su situación en la provincia de León se detalla en el mapa adjunto.

La comarca del Páramo Leonés constituye un espacio perfectamente individualizado del resto de la Meseta a causa de los valles excavados por los ríos Esla y Órbigo, fundamentalmente, y que marcan sus límites oriental y occidental, respectivamente. Ambos ríos excavan un valle de unos dos kilómetros de anchura, que hace resaltar de forma clara el nivel de la Meseta en los dos márgenes. Es por esto que ambos ríos forman los límites naturales de la comarca del Páramo Leonés.

El límite Norte de la comarca no se refleja de forma tan clara como los dos anteriores, y viene marcado por la pérdida de la morfología plana característica de todo el conjunto de la comarca, en la zona de contacto con la Cordillera Cantábrica.

El límite Sur del Páramo está delimitado básicamente por la intersección de los dos grandes ríos que lo recorren de Norte a Sur, como son el Esla y el Órbigo.

Aunque los límites naturales de lo que se conoce como Páramo Leonés parecen claros, la delimitación administrativa exacta de la comarca no parece fija, variando según las fuentes consultadas. Es por esto, y dado que para la realización de un estudio de esta índole se precisa una zona homogénea representativa, se considerarán, en la práctica de este trabajo, como integrantes de la comarca del Páramo Leonés aquellos municipios comunes a los incluidos en las publicaciones consultadas. De esta forma, los municipios considerados incluidos dentro de la comarca del Páramo Leonés son los siguientes: Bercianos del Páramo, Bustillo del Páramo, Laguna Dalga, Laguna de Negrillos, Pobladurade Pelayo García, Pozuelodel Páramo, Roperuelos del Páramo, San Pedro de Bercianos, Santa María del Páramo, Urdiales del Páramo, Valdefuentes del Páramo, Villadangos del Páramo y Zotes del Páramo.

Tradicionalmente el PáramoLeonés se ha dividido a su vez en un Páramo alto y en un Páramo bajo. En el Páramo alto se incluían aquellos territorios de topografia ligeramente más movida y de altitud más elevada, situados en el sector más septentrional, en torno a la cota de los 900 metros. En el Páramo bajo, la altitud se aproxima a los 800 metros, y la superficie es de horizontes mas amplios.

Actualmente esta diferenciación entre Páramo alto y Páramo bajo se encuentra desdibujada, no existiendo una conciencia clara de ambas zonas. Para ello y partiendo como base de la división tradicional de las dos zonas, aquellos municipios que se consideraron incluidos dentro 


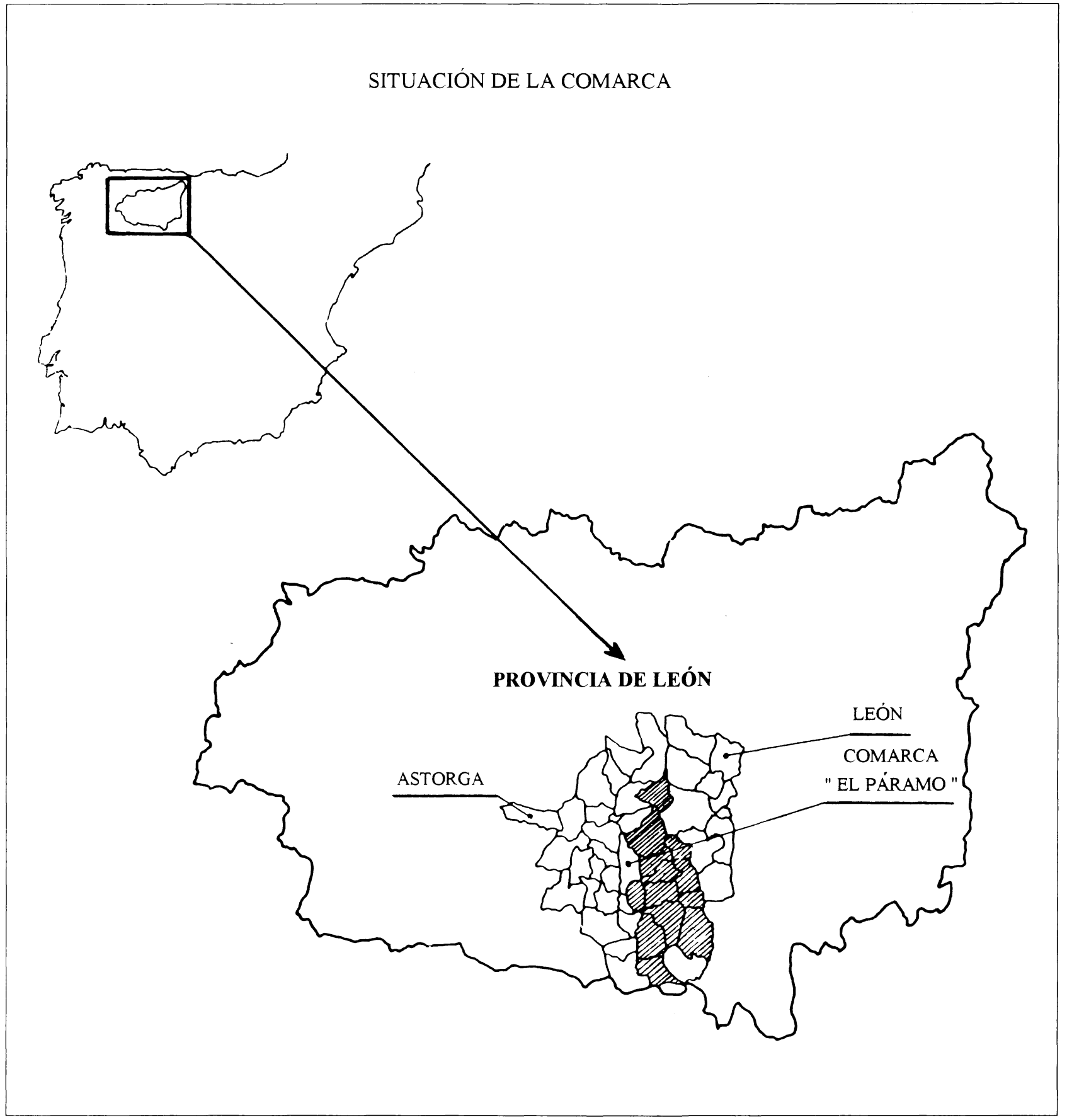

Plano de situación.

de la comarca del Páramo Leonés durante el presente trabajo, se dividieron en Páramo alto y Páramo bajo a partir del límite establecido básicamente por la incidencia territorial de una actuación llevada a cabo por la Administración, como es la transformación de la comarca en regadío. De esta forma, se consideran incluidos en el Páramo alto aquellos municipios que actualmente se encuentran transformados de forma intensa en regadío, $y$, por lo tanto, que aparecen atravesados por una amplia red de canales y acequias; mientras que se incluyen en el Páramo bajo el resto de los municipios de la comarca, que si bien se encuentran en proceso de transformación en regadío, todavía no lo están de forma plena, apareciendo alternados los cultivos tradicionales con los nuevos que introduce el regadío. Esta división actual que se basa en el grado de transformación de la comarca, tiene una correspondencia muy directa con la división tradicional entre Páramo alto y Páramo bajo.

En la Tabla siguiente se indican los municipios que pertenecen a cada una de las zonas en las que se ha dividido la comarca. 


\begin{tabular}{||c|c||}
\hline PÁRAMO ALTO & PÁRAMO BAJO \\
\hline Bustillo del Páramo & Valdefuentes del Páramo \\
San Pedro de Bercianos & Pobladura de Pelayo Garcia \\
Bustillo del Páramo & Zotes del Páramo \\
Bercianos del Páramo & Laguna de Negrillos \\
Urdiales del Páramo & Roperuelos del Páramo \\
Santa María del Páramo & Pozuelo del Páramo \\
Laguna Dalga & \\
\hline
\end{tabular}

Como se verá más adelante, en el estudio y valoración de los paisajes que constituyen la zona, aquellos factores que llevan a dividir la comarca en dos zonas también suponen diferencias en los paisajes que las constituyen y en las tipologías constructivas características de ambas zonas (y por consiguiente en el impacto visual que producen en los diferentes paisajes)

\section{ESTUDIO Y VALORACIÓN DE LOS PAISAJES DE LA ZONA}

Para poder establecer cuáles y cómo son los paisajes que componen la zona, es necesario estudiar, en primer lugar, aquellos elementos propios de la zona que nos pueden ayudar a definir los diferentes paisajes regionales que la constituyen. Estos elementos que se consideran definitorios de cada tipo de paisaje son, básicamente: fisiografia, vegetación y modificaciones antrópicas.

Por tanto, y como resultado de las características fisiográficas, de vegetación y de intervención humanas particulares de la zona, resultarán los distintos paisajes en que podemos dividirla y que, en su conjunto, constituyen el estudio paisajístico de la zona. Cada uno de los distintos tipos de paisaje obtenidos se denominarán "unidades de paisaje" y se describirán y valorarán de forma detallada, de acuerdo con la metodología propuesta.

Pero antes de pasar a estudiar los aspectos propios del paisaje, es necesario describir, al menos de forma breve, la metodología seguida para el establecimiento, delimitación y valoración de las unidades de paisaje, así como para la descripción de los mismos, que se detalla a continuación:

\section{Etapa 1: recopilación cartográfica:}

En primer lugar, para poder analizar los diferentes elementos que constituyen los paisajes de la zona, se procedió a revisar la cartografía existente, que pudiera aportar datos significativos.

Para el estudio de la fisiografía de la zona, se recopilaron los mapas topográficos del Servicio Geográfico Nacional, a escala 1:50.000 de la zona. Dada la homogeneidad topográfica de la zona, se consideró que los datos que dichos mapas proporcionaron eran suficientes para estudiar la influencia de la fisiografía de la zona.

Para la vegetación se estudiaron los mapas de cultivos y aprovechamientos de la zona, a escala 1:50.000. Pero dada la antigüedad de estos mapas (años 1974-77), se consideró que éstos no proporcionarían un fiel reflejo de la vegetación actual, aún más teniendo en cuenta quie desde la fecha de realización de los citados mapas se han realizado profundos cambios en los cultivos que constituyen de forma fundamental la vegetación de la zona, como son los trabajos de concentración parcelaria y la implantación de los sistemas de regadío. Por tanto, y para poder obtener datos fiables y actualizados, se decidió estudiar y delimitar los cambios de la vegetación de la zona in situ

Mientras se cartografiaba la vegetación, sobre el terreno, también se analizaron y cartografiaron los factores de modificación antrópica en los paisajes.

\section{Etapa 2: toma de datos de campo:}

Sobre una base cartográfica a escala 1:50.000 y apoyado con el estudio en gabinete de la ortoimagen espacial, a escala 1:100.000 y la fotografía aérea de la zona (se utilizó un vuelo fotogramétrico de julio de 1990, a escala 1:20.000), se recogieron sobre el terreno aquellos valores de la fisiografia, la vegetación y de las modificaciones antrópicas que tenían influencia sobre los paisajes de la zona, apoyados en la extensa red de carreteras de distintos órdenes y de caminos que atraviesan la zona.

Etapa 3: establecimiento y delimitación de las unidades paisajisticas:

A partir de los datos físiográficos, de vegetación y de intervención humana particulares de la zona y recogidos durante la etapa 2, se delimitaron como unidades paisajísticas aquellas zonas que presentaban características comunes, que las diferenciaban con claridad del resto, componiendo, de esta manera, la totalidad del paisaje de la zona. Es decir, paisajísticamente, todo el conjunto de la zona queda dividido en unidades de paisaje.

\section{Etapa 4: descripción de las unidades de paisaje:}

Una vez dividida la zona de estudio en unidades de paisaje, se procedió a la descripción detallada de cada una de éstas. Para ello se utilizó la fícha "Inventario de los recursos del paisaje", que forma parte del método de valoración del paisaje propuesto por D. Ignacio Cañas Guerrero, y que se describe más adelante. En primer lugar, se eligieron una serie de puntos característicos de observación de cada una de las unidades de paisaje. Posteriormente se realizó una nueva visita a la zona y, desde cada uno de los puntos característicos antes mencionados, se rellena la ficha correspondiente a cada unidad de paisaje y se toma una 
fotografia representativa. En esta ficha se detallan cada uno de los atributos y variables que componen cada una de las unidades paisajísticas, con lo que éstas quedan perfectamente descritas. Para cada unidad de paisaje se cumplimentan varias fichas (una para cada punto característico incluido en dicha unidad).

\section{Etapa 5: valoración de las unidades de paisaje:}

Una vez cumplimentadas las fichas de inventario de los recursos del paisaje en el campo, se procedió, en el gabinete, a la valoración de cada una de las unidades de paisaje. Para realizar la valoración, se parte básicamente de las fichas de inventario de los recursos del paisaje, puntuando cada uno de los atributos y variables que lo componen de acuerdo con el método de valoración propuesto.

\subsection{Estudio de los paisajes regionales}

Antes de establecer y delimitar las diferentes unidades de paisaje que componen la zona objeto del estudio, se detallan los principales elementos que definen los distintos paisajes regionales. Estos elementos que constituyen el estudio de los paisajes regionales de la zona son:
a) fisiografia.
b) vegetación.
c) modificaciones antrópicas.

No existe ninguna zona que presente algún grado de protección ambiental, ni tampoco ninguna otra propuesta para ser incluida en zonas de protección, por lo que no se tendrá en cuenta para el establecimiento de las unidades paisajísticas ninguna limitación de este tipo.

\section{a) Fisiografia:}

En cuanto a la fisiografia, todo el conjunto de la zona presenta una notable homogeneidad.

Es por esto, por lo que para la delimitación de los diferentes paisajes de la zona, la fisiografia no tiene apenas influencia, de forma que prácticamente todo el conjunto de los paisajes regionales presentan unas características fisiográficas similares, definidas por una morfología llana, con unos desniveles muy escasos.

Esta homogeneidad fisiográfica se ve ligeramente truncada si se recorre la zona en sentido Este a Oeste, donde la sensación de llanura tan perfecta desaparece en parte, como consecuencia de ligeras vallinas que atraviesan la zona en sentido Norte-Sur y que han sido excavadas por los riachuelos que recorren la zona. Su influencia en el paisaje local no es muy importante, ya que el relieve llano se recupera rápidamente, aunque a lo largo de un buen número de dichas vallinas sí se puede observar un cambio más acusado en la vegetación presente.
El mismo efecto anterior, pero de forma más acusada, se detecta en las proximidades del río Órbigo, donde las terrazas, que constituyen la fisiografía característica de la zona, van descendiendo, en suave escalonamiento, hacia los lechos del río. Por tanto, en la zona de influencia del río Órbigo, sí se pueden apreciar diferencias fisiográficas, que influirán de forma notable en el paisaje.

\section{b) Vegetación:}

Al contrario que la fisiografía, es la vegetación la que va a definir, principalmente, las diferencias paisajísticas de la zona, en pocas ocasiones ayudada por las singularidades fisiográficas.

En cuanto a la vegetación, se encuentran representadas en la zona de estudio los siguientes tipos:

\section{1.- Cultivos de regadio}

Dentro de éstos se pueden distinguir dos tipos:

Monocultivos intensivos de maíz. Es el cultivo que aparece más frecuentemente representado y el que ocupa una mayor extensión en toda la zona.

Huertas. Frecuentemente de remolacha-alubia-cereal. En general, y salvo contadas excepciones, ocupan extensiones pequeñas y suelen aparecer de forma dispersa entre los cultivos intensivos de maíz.

\section{2.- Cultivos de secano}

Ocupa terrenos dedicados a cultivos herbáceos de secano. Los cultivos de secano más abundantes son, por orden descendente de representación, trigo, cebada, avena y centeno.

\section{3. - Cultivos de secano con matorral disperso}

Se trata de cultivos de secano abandonados, generalmente viñedos con cepas de elevada edad, que anteriormente se explotaban en monocultivo y que están siendo invadidos por matorral de pequeña talla de coscoja (Quercuscoccifera) y encina (Quercusilex ssp. rotundifolia) de forma progresiva, según se ha ido dejando su explotación. Por tanto, se corresponde con terrenos abandonados en los que no se efectúa ninguna labor cultural.

\section{4. - Pastizales}

Se trata, casi en su totalidad, de pastos comunales que pueden ser aprovechados exclusivamente por pastoreo.

\section{5.- Pastizal-matorral}

Se trata de formaciones de pastizal y matorral disperso de 
encinas (Quercus ilex ssp. rotundifolia) y sobre todo de rebollo (Quercus pyrenaica), que en algunos casos presentan porte arbóreo además del arbustivo. El pastizal se explota por pastoreo con ganado ovino, pero de forma esporádica, mientras que el rebollo complementael pastoreo con frutas, ramón y descansadero.

\section{6.- Choperas}

Estas formaciones están constituidas por diferentes híbridos de chopo (Populus sp.). Las masas de esta especie están localizadas principalmente en la ribera del río Órbigo, constituyendo choperas de gran entidad. Su único aprovechamiento es el maderero, con turnos de corta que varían entre los doce y los quince años, como media.

También son significativas las plantaciones de chopos que se encuentran en las cercanías de los diferentes riachuelos que atraviesan la zona. Estas son choperas de menor envergadura que las citadas anteriormente, constituidas generalmente por varias filas de chopos a ambos lados del río.

De la misma forma que las anteriores se presentan las choperas que se sitúan a lo largo de un gran número de los canales y acequias que recorren la zona.

También pueden encontrarse pequeñas choperas, inclusoárboles dispersos, mezclados con los cultivos de regadío, especialmente en las zonas más próximas a los núcleos urbanos.

\section{7.- Formaciones en galería}

Envolviendo el cauce de algunos pequeños arroyos, se encuentran pequeñas formaciones en galerías, constituidas fundamentalmente por Populus nigra, Populus euroamericana, Salix necalliana, Salix angustifolia, Ulmus minory Juncus sp. Estas formaciones tienen una representación muy escasa.

\section{8. - Encinar}

Está constituido por masas de encinar (Quercus ilex ssp. rotundifolia) adehesado. Las masas de encinar pueden encontrarse en estado arbóreo y arbustivo, bien de forma aislada o en asociación de ambos portes, variando la fracción de cabida cubierta entre el $40 \%$ y el $80 \%$. Éstos se corresponden con bosques relícticos de una vegetación autóctona actualmente muy transformada por el hombre, para su aprovechamiento.

El aprovechamiento hace años de estos encinares era la obtención de carbón de encina, por lo que se le dieron grandes talas, lo que ha sido decisivo en su estado actual. En la actualidad el aprovechamiento es muy escaso, pues no se utiliza más que para la obtención de leña o esporádicamente para la obtención de madera.

\section{c) Modificaciones antrópicas:}

Además de la fisiografia y la vegetación, los últimos elementos que completan el estudio de los paisajes regionales de la zona son las modificaciones antrópicas̀

Estas modificaciones del paisaje producto de la intervención directa del hombre, se pueden clasificar, en la zona objeto de estudio, en:

\section{1.- Zonas urbanas}

Se refiere, evidentemente, a los núcleos de población, que según su tamaño, interrumpen en mayor o menor grado el paisaje. Al ser la fisiografia eminentemente llana, la silueta de los pueblos puede verse desde varios kilómetros de distancia, destacando por encima de la vegetación, por lo que su influencia en el paisaje es notable.

\section{2.- Zonas afectadas por la expansión urbana}

Se refiere a las zonas inmediatamente próximas a las zonas urbanas. En estas zonas que rodean las poblaciones, lo más destacable son las construcciones producto de la industrialización.

Las construcciones suelen ser de mayor envergadura que el resto de construcciones incluidas dentro del núcleo de población, tanto en anchura como en altura, por lo que su influencia en el paisaje es la de resaltar aún más la interrupción de los núcleos urbanos en la vegetación.

Estas construcciones periurbanas suelen aparecer ya mezcladas con los distintos tipos de cultivos y vegetación que rodean a los núcleos urbanos, y que presentan características singulares.

\section{3.- Zonas afectadas por la red de transporte}

Dentro de las zonas afectadas por la red de transporte podemos distinguir, según su grado de influencia en el paisaje regional, los siguientes tipos:

\section{- Carreteras nacionales:}

Se trata de una modificación lineal del paisaje, que atraviesa diferentes tipos de vegetación. Debido a su anchura y a encontrarse elevadas sobre el terreno, son visibles desde bastantes kilómetros de distancia. Además de la carretera en sí, aparecen a lo largo de ella una serie de construcciones e infraestructuras características de este tipo de carreteras (estaciones de servicio, naves industriales, restaurantes,...) que acentúan aún más su influencia en el paisaje. 
La influencia de este tipo de carreteras en el paisaje no es únicamente visual, sino que también aportan un elevado indice de ruidos y un alto grado de presencia humana.

\section{- Líneas de ferrocarril}

Al igual que las carreteras nacionales, las líneas de ferrocarril, en la zona de estudio, aparecen elevadas sobre el terreno, por lo que aumenta su interrupción en el paisaje. Además, las líneas de ferrocarril presentan a lo largo de todo su recorrido una serie de construcciones verticales (postes de mayor o menor envergadura), que incrementan su grado de intrusión en el paisaje y que pueden verse desde bastante distancia.

\section{- Carreteras de menor orden:}

Dentro de este tipo se incluyen el resto de carreteras, exceptuando las nacionales, que recorren la zona. Son, por tanto, carreteras comarcales o de menor orden, que aparecen asfaltadas sólo en algunas ocasiones. Ninguna de estas carreteras aparecen elevadas sobre el terreno

Al no estar elevadas sobre el terreno y al ser la morfología de la zona llana, estas carreteras apenas pueden apreciarse desde fuera, estando tapadas por la vegetación que las rodea (sobre todo cuando los cultivos son de regadío, ya que éstos son de mayor altura) y, por tanto, no produciendo apenas interrupciones en el paisaje. Es por esto por lo que la influencia de estas carreteras en el paisaje es muy pequeña.

Sí se producen aportaciones de mayor importancia al paisaje en algunas carreteras de este tipo, que aparecen limitadas por una fila de chopos a cada lado, y que la acompañan durante parte de su recorrido. Estas choperas lineales que recorren las carreteras interrumpen el paisaje local, enriqueciéndolo en mayor o menor grado.

\section{4.- Red de canales y acequias}

La zona se encuentra atravesada por una amplia red de canales y acequias.

Los canales principales suelen ir enterrados en el suelo, y acompañados en su recorrido por una fila de chopos a cada lado. De esta forma, estos canales introducen en el paisaje dos nuevos factores, la presencia de agua x la aparición de un arbolado, que destacan de forma importante en el paisaje.

Dentro de las acequias de menor envergadura hay algunas que se encuentran enterradas o al nivel del suelo, y otras que aparecen sobre el nivel del suelo. Por tanto estas últimas son las que interrumpen en mayor grado el paisaje, atravesando a unos 20 centímetros del suelo, la vegetación de la zona.

\section{5. - Líneas eléctricas y telefónicas}

Como consecuencia del alto grado de intervención humana en la zona, puede observarse que todo el territorio se encuentra recorrido por una abundante red de líneas, tanto eléctricas como telefónicas, que introducen elementos particulares en el paisaje, como son las construcciones verticales (postes).

Debido a su abundancia, estas modificaciones no se han cartografiado, pero hay que tener en cuenta que estas líneas eléctricas y telefónicas van a estar presentes en prácticamente todos los paisajes de la zona, por lo que habrá que considerarlas como un elemento más del paisaje.

\subsection{Delimitación de las unidades paisajísticas}

Como resultado de la combinación de las tres variables, la fisiografia, la vegetación y las modificaciones antrópicas, particulares de la zona de estudio, se obtienen las distintas unidades de paisaje que constituyen el conjunto paisajístico de la zona. Por tanto cada una de las unidades de paisaje en las que se divide el territorio presenta unas características fisiográficas, de vegetación y de intervención humana particulares, que las hacen paisajísticamente homogéneas y distintas del resto.

A continuación se enumeran las diferentes unidades de paisaje que se delimitaron en la zona, además de hacerse una breve descripción de las mismas. La descripción detallada de cada una de las unidades de paisaje se realiza mediante la mencionada ficha de "inventario de los recursos del paisaje", que se describe en el siguiente apartado del presente estudio.

\section{1.- Paisajes de regadío}

Dentro de los paisajes de regadío se distinguen dos tipos, que si bien presentan características comunes, como es su aprovechamiento agrícola en regadío, en cuanto a paisaje presentan algunas características específicas que permiten distinguirlos:

\subsection{Monocultivo intensivo en regadio:}

Se trata de paisajes con morfologías generalmente llanas, con una vegetación constituida exclusivamente por cultivos de maíz, explotados en regadío de forma intensiva y que presenta una talla y una envergadura homogénea. Por tanto, se trata de un paisaje extraordinariamente monótono, que sólo se ve interrumpido por las modificaciones que introduce la intervención humana.

Las modificaciones más frecuentes son las acequias y canales de pequeña envergadura que a distintas alturas atraviesan los cultivos y que distribuyen el agua en los mismos. También aparecen con cierta frecuencia caminos 
y carreteras (algunas de ellas asfaltadas) que atraviesan los cultivos, pero que debido a su poca anchura y a la altura de los cultivos, apenas destacan sobre el paisaje. Sí destacan en el paisaje las líneas eléctricas y telefónicas que lo atraviesan, ayudadas, además, por la fisiografía llana y homogénea de la zona.

En resumen se trata de unos paisajes homogéneos en cuanto a vegetación y fisiografía, que sólo parecen ser interrumpidos por los postes y líneas de conducción. Las vistas que presentan, por tanto, son panorámicas

\subsection{Mosaico de cultivos en regadio}

Las características generales fisiográficas y de intervención humana son similares a las reseñadas en el paisaje anterior. Tan sólo se presentan diferencias en cuanto a la vegetación, donde los cultivos de maíz se ven interrumpidos, con mayor o menor frecuencia, por manchas de huertas de distintos cultivos (remolacha, alubias, cereales,...). De esta manera se introduce en el paisaje una mayor diversidad de vegetación. Estos cultivos aparecen con unas tallas menores, generalmente pegados al suelo, por lo que se presenta un mayor contraste en las formas dominantes del paisaje y también en el color de los distintos cultivos. Por otrolado laintrusión de las modificaciones humanas se realiza de igual manera que en los cultivos intensivos de regadío.

\section{2.- Pastizal - Matorral}

Éste es un paisaje más diverso que el anterior. Si bien la morfología continúa siendo llana, la vegetación presenta una variación ·mucho mayor, alternándose las herbáceas rastreras con el matorral de rebollo y de encina, que en ocasiones presenta portes arbóreos. El resultado es un paisaje con una mayor variación de formas, pero sin que se introduzcan otros factores distintos. Las modificaciones antrópicas son escasas y poco visibles, por tanto, el paisaje se ve en pocas ocasiones interrumpido por ellas

\section{3.- Bosques de frondosas}

Dentro del grupo de paisajes de bosques de frondosas, podemos distinguir dos unidades paisajísticas claramente distintas:

\subsection{Choperas}

Son paisajes que ocupan pequeñas extensiones, exceptuando los que se encuentran en las cercanías del río Órbigo que son formaciones más extensas. La fisiografía continúa siendo llana, y la vegetación está compuesta de forma exclusiva por chopos de una edad máxima comprendida entre doce y quince años, pero siempre homogénea. El suelo está cubierto por herbáceas de talla baja. Las choperas situadas en las cercanías de los ríos introducen en el paisaje un factor más, como es la presencia del agua.

Si bien estos paisajes no son muy ricos en diversidad, sí proporcionan a los paisajes que les rodean un mayor contraste en las formas.

\subsection{Encinares adehesados}

Se trata de los paisajes más ricos y diversos de todos los que componen la zona objeto de estudio.

La vegetación presenta una diversidad importante, tanto en lo que se refiere a especies como a portes. De esta forma se encuentran herbáceas bajas, matorral de pequeña talla y diversas especies, matorral alto de encinas y encinas con porte arbóreo. La cabida cubierta del encinar es también variable, desde un $40 \%$ hasta un $80 \%$. Las modificaciones antrópicas son muy escasas y apenas visibles. Es un paisaje generalmente bastante cerrado, con una limitación de las vistas importante.

\section{4.- Formaciones lineales de frondosas}

Se trata de paisajes compuestos por una fisiografia llana y una vegetación formada por choperas, con porte arbóreo, dispuesta en dos filas a ambos lados de riachuelos, ríos y carreteras. En las formaciones de estos paisajes que siguen el curso de riachuelos y canales, se introduce un elemento enriquecedor del paisaje, como es la presencia de cursos de agua. En las primeras, formaciones a lo largo de los riachuelos, el grado de intrusión humana es inapreciable, mientras que en los canales las modificaciones antrópicas están presentes, por las construcciones propias de los canales y acequias, aunque no son dominantes. En cambio, en aquellos paisajes lineales propios de las carreteras, la intervención humana es muy patente, sustituyéndose el elemento agua por la carretera, en la mayoría de los casos asfaltadas.

En cualquier caso se trata de formaciones paisajísticas con una estructura lineal dominante, que atraviesan otras unidades de paisajes propias de la zona, lo que produce un enriquecimiento de estos paisajes atravesados, mediante la incorporación en el plano de fondo de estructuras arbóreas (los paisajes que atraviesan son siempre los correspondientes a formaciones de vegetación de talla poco elevada, que permiten observar el plano de fondo)

\section{5. - Formaciones en galería}

Aparecen a lo largo del cauce de algunos riachuelos, envolviéndolos. Son unidades pequeñas, con la fisiografía característica de los pequeños cursos de agua encajados en el terreno. Es un paisaje muy cerrado, con una vegetación diversa en cuanto a especies, pero muy similar en 
cuanto a aspecto, talla y colores. El grado de intrusión humana en estos paisajes es prácticamente nulo. Dentro de estos paisajes las vistas son muy limitadas, y al estar algo encajados en el terreno, tampoco son fácilmente apreciables desde fuera, por lo que no constituyen un elemento enriquecedor de los paisajes colindantes.

\section{6.- Mosaico de cultivos de regadio y secano}

Son formaciones que ocupan amplias extensiones de terreno, en las que domina la alternancia entre cultivos herbáceos de regadío y de secano. Los cultivos de regadío son más altos y de colores más vivos y brillantes que los de secano, por lo que el paisaje está dominado por el contraste de ambos cultivos, unido a las formas llanas del terreno, características de toda la zona. El grado de intervención humana en la zona es claramente apreciable, destacando las construcciones propias de las conducciones de agua en los cultivos de regadío, y las casetas y demás construcciones agrícolas por toda la zona.

\section{7.- Secano intensivo}

Son formaciones paisajísticas sobre terrenos de nuevo llanos y con una vegetación herbácea baja, constituida por cultivos propios de secano. La intervención humana es patente y fácilmente apreciable debido a lo llano del terreno y a la escasa talla de la vegetación. El resultado es, por tanto, un paisaje extremadamente homogéneo en sus características, únicamente interrumpido por las construcciones propias de la zona: casetas agrícolas, naves, líneas de conducción eléctrica y telefónica,..

\section{8.- Secano degradado}

La topografia continúa siendo llana. La vegetación está constituida por cultivos de secano abandonados, generalmente viñedos, invadidos parcialmente por formaciones de matorral rastrero. El grado de intrusión humana es más escaso que en el paisaje anterior, pudiendo observarse únicamente algunas construcciones abandonadas y en estado de deterioro. El resultado es un paisaje también homogéneo, propio de terrenos abandonados, en los que no se aprecian labores culturales.

\section{9.- Poblaciones}

Los núcleos de población son abundantes, y aparecen dispersos por toda la zona. Sus siluetas son alargadas, de forma perpendicular a las carreteras de entrada. De la silueta principal destacan las torres pertenecientesa iglesias y depósitos de agua. Los colores de las poblaciones no ofrecen mucho contraste con el medio que les rodea, por lo que parecen integrarse en el paisaje. En las poblaciones con mayor desarrollo, y en menor medida en el resto, se sitúan en las zonas periurbanas una serie de construcciones industriales y agrícolas de grandes proporciones, realizadas con materiales constructivos nuevos y colores generalmente llamativos y disonantes con los de las construcciones tradicionales, que rompen la silueta típica de estos núcleos de población, por lo que la integración con el paisaje circundante es muy escasa.

Aunque los núcleos de población constituyen paisajes claramente distintos de los ya mencionados, tanto éstos, como las construcciones que se encuentran en ellos, no serán objeto de valoración en el presente estudio.

\section{0.- Modificaciones lineales del paisaje}

Se refiere a las carreteras nacionales y líneas de ferrocarril que atraviesan la zona. Debido a su envergadura, a encontrarse elevadas sobre el terreno y a la presencia de un gran número de construcciones asociadas, se han considerado modificaciones lineales de los paisajes de tal envergadura, que se consideran como paisajes distintos al resto (sus características se describieron en el apartado dedicado a los paisajes regionales).

$\mathrm{Al}$ igual que en las poblaciones, no se tendrán en cuenta en la valoración del paisaje ni en la del impacto visual, por quedar fuera de los objetivos del presente estudio.

En el mapa de la siguiente página aparecen delimitadas cada una de las unidades de paisaje presentes en la zona.

\subsection{Valoración de las unidades paisajísticas de la zona}

Para la valoración de las distintas unidades de paisaje que componen el conjunto de paisajes de la zona se utiliza un método concreto, que se adapta correctamente a las características propias de la zona de estudio (Cañas, I., 1992).

Antes de exponer los resultados de la valoración de cada una de las unidades de paisaje, se describe, de forma muy breve, el método utilizado.

Como se hizo referencia en la introducción, en la valoración del paisaje existe un claro conflicto entre diferentes enfoques; el método utilizado para la valoración de las unidades paisajísticas en este trabajo, pretende estudiarlo desde las diversas perspectivas, considerando así atributos físicos, descriptores artísticos y descriptores psicológicos.

Como atributos físicos se consideran en el proceso de valoración los siguientes:

1.- Agua (se incluye 4 variables: tipo, orillas, movimiento y cantidad).

2.- Forma del terreno (1 variable: tipo).

3.- Vegetación (4 variables: cubierta, diversidad, calidad y tipo). 


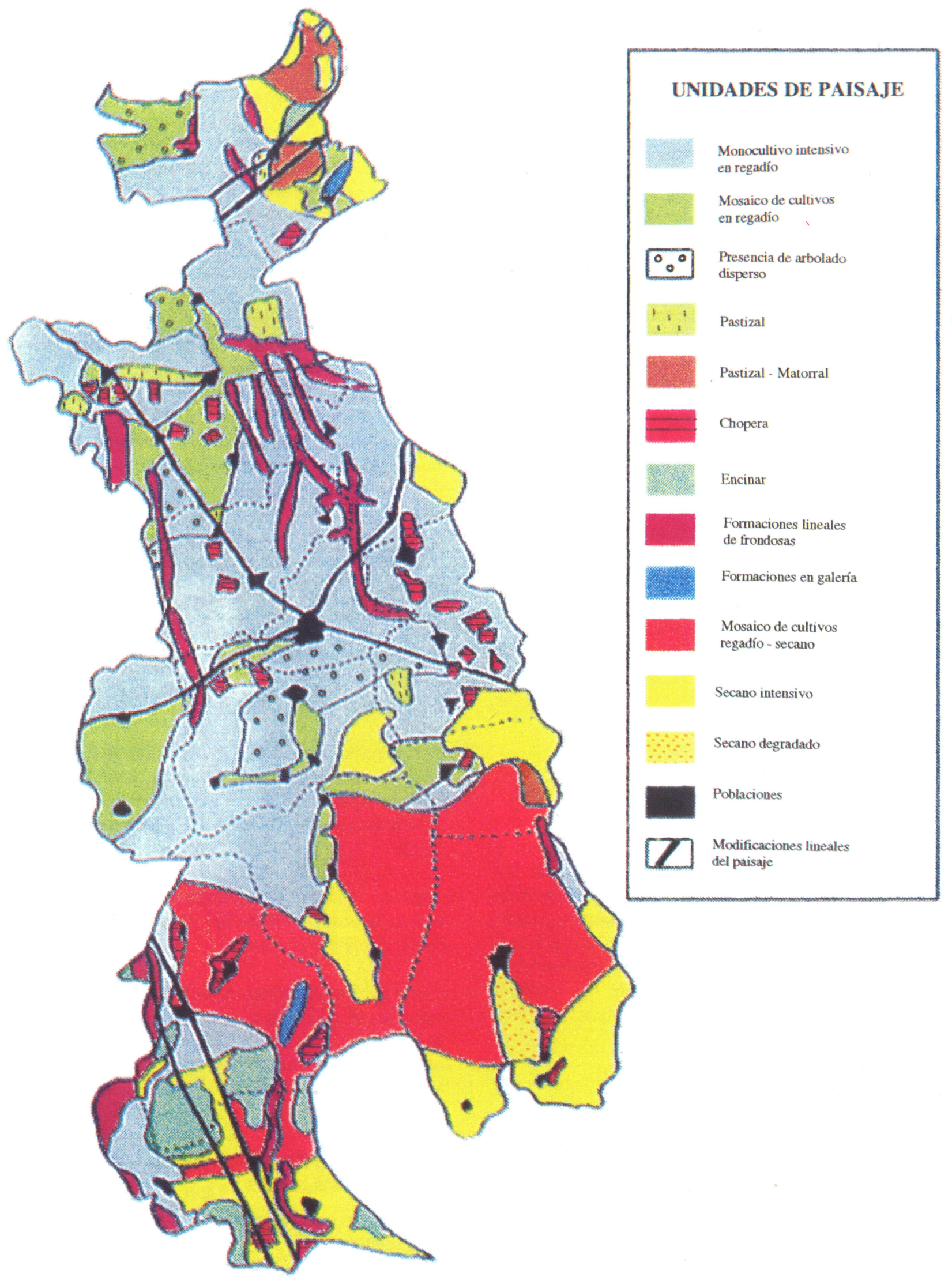

Unidades de paisaje en la zona. 
4.- Nieve (1 variable: cubierta).

5.- Fauna (3 variables: presencia, interés y facilidad de verse).

6.- Usos del suelo (2 variables: tipo e intensidad).

7.- Vistas (2 variables: amplitud y tipo)

8.- Sonidos (2 variables: presencia y tipo).

9.- Olores (2 variables. presencia y tipo).

10.- Recursos culturales (4 variables: presencia, tipo, facilidad de verse e interés)

11.- Elementos que alteran el carácter (4 variables: intrusión, fragmentación del paisaje, tapa línea del horizonte y tapa vistas).

Es decir, se estudian 11 descriptores físicos con un total de 33 variables.

Con relación a los descriptores artísticos, se estudian los siguientes:

1.- Forma (3 variables: diversidad, contraste y compatibilidad).

2.- Color (3 variables: diversidad, contraste y compatibilidad).

3.- Textura (3 variables: diversidad, contraste y compatibilidad).

Es decir, se estudian 3 descriptores artísticos, con un total de 9 variables.

Por lo que se refiere a los descriptores psicológicos se tienen en cuenta los siguientes:

1.- Unidad (2 variables: líneas estructurales y proporción).

2.- Expresión (3 variables: afectividad, estimulación y simbolismo).

Es decir, se estudian 2 descriptores con un total de 5 variables.

En el modelo de ficha que se incluye para la valoración de las unidades de paisaje, los descriptores aparecen agrupados en atributos físicos, correspondientes a los descriptores físicos, y atributos o recursos estéticos, correspondientes a los descriptores artísticos y psicológicos. Dentro de los atributos físicos, los que se pueden valorar mediante fotografías (en principio todos menos los olores y los sonidos) aparecen agrupados como recursos visuales. También se incluye en la ficha un apartado de visibilidad, en los que se reflejan los atributos basados en las características de los observadores.

La puntuación que se da a cada tipo de paisaje se establece mediante una puntuación de 0 a 100 . De esta forma el método posee un alto grado de sensibilidad, es decir, que es sensible a pequeños cambios que sucedan en el paisaje, al quedar éstos reflejados en la valoración o en sus notas.
Por otra parte, al separar los llamados recursos físicos de los estéticos, podemos saber si la calidad se debe a unos o a otros.

Con el fin de que la estimación no se vea influenciada por los elementos distorsionadores no se considera en el paisaje ni el cielo, ni los elementos del primer plano (0-50 m); no obstante, para la valoración de las vistas se consideran los elementos a partir de $300 \mathrm{~m}$.

Como se mencionó antes, la puntuación final de cada unidad de paisaje se establece de 0 a 100 , y con la puntuación obtenida se realiza una clasificación del paisaje de acuerdo con la Tabla que se expone a continuación:

\begin{tabular}{||c|c||}
\hline \multicolumn{2}{|c|}{ CLASIFICACIÓN GLOBAL } \\
\hline$<20$ & Degradado \\
$20 \cdot 32$ & Deficiente \\
$32 \cdot 44$ & Mediocra \\
$44 \cdot 56$ & Buena \\
$56 \cdot 68$ & Notable \\
$68 \cdot 80$ & Muy buena \\
$>80$ & Excelente \\
\hline
\end{tabular}

La puntuación de los diversos atributos viene establecida en la descripción del método de valoración utilizado (Cañas I, 1992).

La descripción de cada uno de los descriptores y de sus variables, así como la valoración de los mismos, se realiza mediante unaficha, que se rellena deforma independiente para cada una de las unidades de paisaje. Esta ficha puede rellenarse a partir de una fotografía donde se refleje el paisaje que quiere valorarse y describirse, pero en este estudio se ha elaborado en el campo, desde una serie de puntos que se consideran como característicos de cada tipo de paisaje.

La totalidad de las fichas correspondientes a cada uno de los puntos característicos desde los que se cumplimentaron las fichas de "inventario de los recursos del paisaje", con las que se describen las diferentes unidades de paisaje, no se incluyen en el artículo debido a su volumen. Sí se incluye a continuación una de las fichas, para que pueda servir de ejemplo, correspondiente a una de las unidades de paisaje valoradas, acompañada de una fotografía representativa de la zona. También se adjunta el resumen global de la clasificación de todas las unidades de paisaje.

La ficha se rellenó de la siguiente forma: en cada atributo aparece una casilla cerca del número, en esta casilla se debe poner una $\mathrm{X}$ si el paisaje no tiene ese atributo y una $\mathrm{V}$ en caso contrario; cada atributo lleva una serie de variables que van encabezadas con una letra, si el paisaje contiene la 
variable, se rodea con un círculo la caracterización de la variable que corresponde a ese paisaje, dejándose en blanco en caso contrario; de esta forma si el paisaje no tiene un determinado atributo no hace falta que se especifique que tampoco tiene ninguna de sus variables.

A continuación se exponen, de forma resumida, los resultados de la valoración de las distintas unidades de paisaje que componen la zona de estudio, como resultado

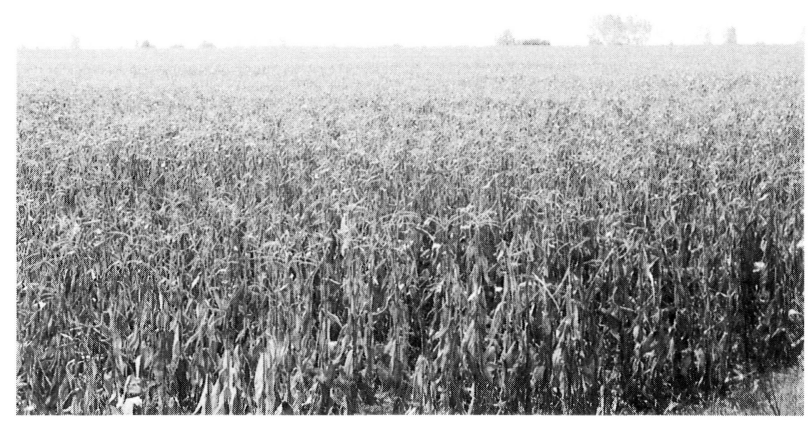

Monocultivo intensivo de regadio.

\section{INVENTARIO RECURSOS PAISAJE}

PTO DE OBSERVACIÓN: MONOCULTIVO INTENSIVO EN REGADIO

HOJA

ATRIBUTOS FÍSICOS

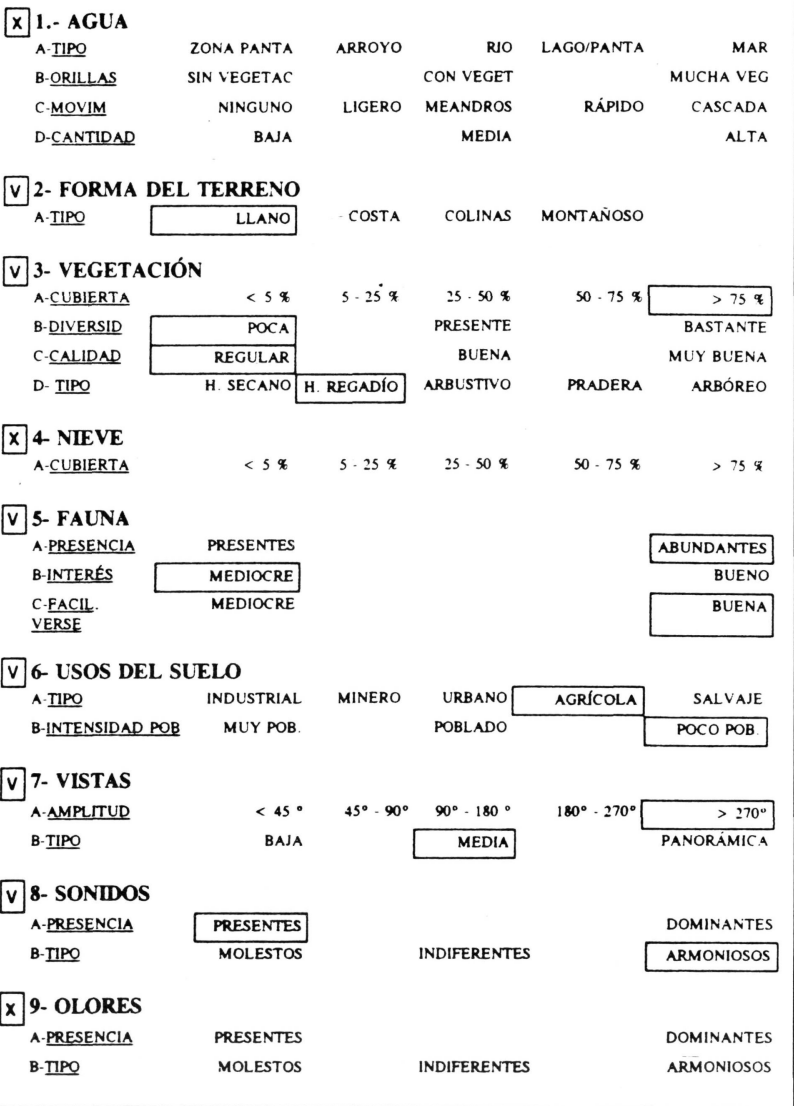

(c) Consejo Superior de Investigaciones Científicas Licencia Creative Commons 3.0 España (by-nc)

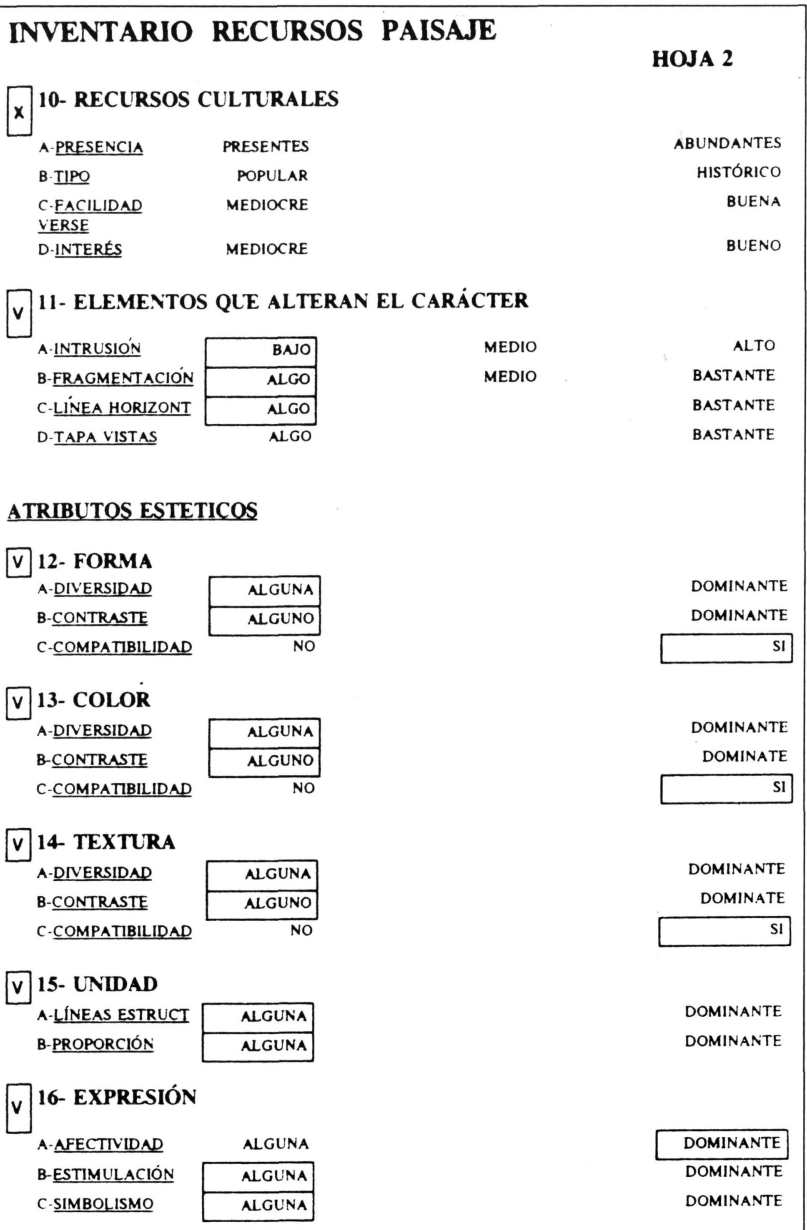

VALORACIÓN GENERAL DEL PAISAJE

HOJA 1
ATRIBUTOS FISICOS

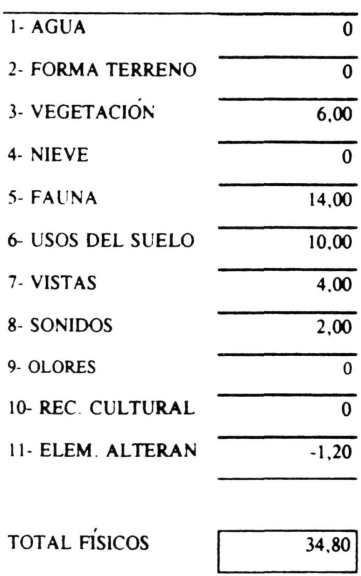

TOTAL RECURSOS

\section{ATRIBLTOS ESTÉTICOS}

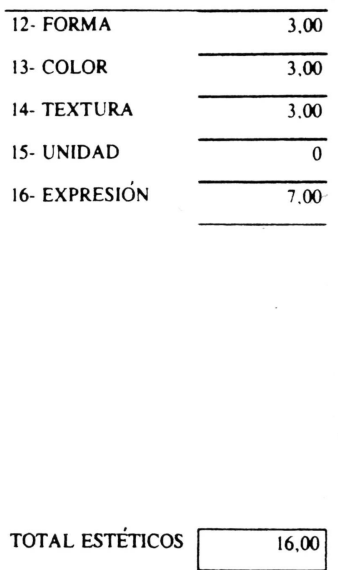

\section{CLASIFICACIÓN GLOBAL}

\begin{tabular}{|c|c|}
\hline$<20$ & DEGRADADO \\
\hline $20-32$ & DEFICIENTE \\
\hline $32-44$ & MEDIOCRE \\
\hline $44-56$ & BLENO \\
\hline $56-68$ & NOTABLE \\
\hline $68-80$ & MUY BUENO \\
\hline$>80$ & EXCELENTE \\
\hline
\end{tabular}




\begin{tabular}{|c|c|c|c|c|}
\hline UNIDAD PAISAJÍSTICA & $\begin{array}{l}\text { ATRIBUTOS } \\
\text { FÍSICOS }\end{array}$ & $\begin{array}{l}\text { ATRIBUTOS } \\
\text { ESTÉTICOS }\end{array}$ & TOTAL & CLASIFICACIÓN \\
\hline Monocultivo intensivo en regadío & 36,80 & 16,00 & 52,80 & Bueno \\
\hline Mosaico de cultivos en regadío & 29,25 & 22,00 & 51,25 & Bueno \\
\hline $\begin{array}{l}\text { Regadio con arbolado } \\
\text { disperso }\end{array}$ & 44,37 & 21,00 & 65,37 & Notable \\
\hline Pastizal & 23,30 & 9,00 & 32,30 & Mediocre \\
\hline Pastizal-Matorral & 44,50 & 15,00 & 59,50 & Notable \\
\hline Chopera & 27,00 & 41,00 & 68,00 & Notable \\
\hline Encinares & 47,50 & 30,00 & 77,50 & Muy bueno \\
\hline $\begin{array}{l}\text { Formaciones lineales de Frondo- } \\
\text { sas (carreteras) }\end{array}$ & 6,00 & 39,00 & 45,00 & Bueno \\
\hline $\begin{array}{l}\text { Formaciones lineales de Frondo- } \\
\text { sas (canales) }\end{array}$ & 28,00 & 45,00 & 73,00 & Muy bueno \\
\hline Formaciones en galería & 39,75 & 35,00 & 74,75 & Muy bueno \\
\hline $\begin{array}{l}\text { Mosaico de cultivos de regadio } y \\
\text { secano }\end{array}$ & 28,00 & 16,00 & 44,00 & Mediocre \\
\hline Secano intensivo & 27,50 & 16,00 & 43,50 & Mẹdiocre \\
\hline Secano degradado & 22,75 & 9,00 & 31,75 & Deficiente \\
\hline
\end{tabular}

de aplicar la metodología antes descrita Para ello se ha cumplimentado una ficha de inventario de los recursos del paisaje y de valoración, como la incluida, para cada uno de los puntos característicos de observación elegidos. Por tanto, para cada una de las unidades de paisaje aparecen varias fichas de valoración, correspondientes a los diferentes puntos característicos incluidos en cada unidad de paisaje, presentando ligeras modificaciones en su puntuación, en función de la aparición de unas $u$ otras variables. Aunque como se ha dicho, la puntuación de cada unidad de paisaje puede sufrir ligeras variaciones de unos puntos de observación a otros, su clasificación final no varía.

Las valoraciones que se incluyen en la Tabla anterior corresponden a los puntos de observación que se consideraron característicos para cada unidad de paisaje.

\subsection{Conclusiones}

Casi la totalidad de los paisajes del Páramo Leonés presentan una característica común, la profunda intervención humana a la que se han visto sometidos. Es por esto que se trata de paisajes muy asociados al hombre, presentando unas características muy particulares, difícilmente observables en otras zonas.
La división tradicional de la comarca en dos zonas, Páramo alto y Páramo bajo, también se refleja actualmente de forma clara en el paisaje.

De esta forma, el paisaje característico del Páramo alto es el regadío, bien de forma intensiva o en mosaico de cultivos, ocupando la mayor parte de la zona. Estos paisajes son, evidentemente, consecuencia de la transformación de la comarca en regadío, y particularmente en el Páramo alto, donde esta actuación ha provocado una profunda transformación del paisaje, lo que puede observarse comparando con los paisajes característicos del Páramo bajo, donde la transformación en regadío todavía se encuentra en desarrollo.

Por otro lado, el Páramo bajo se caracteriza por paisajes de secano intensivo. Aunque, como ya se mencionó anteriormente, el Páramo bajo no se encuentra transformado de forma intensa en regadío, sí empiezan a observarse los cultivos propios de regadío alrededor de los canales de agua que proceden del Páramo alto. Este hecho se puede apreciar, por tanto, en el Norte del Páramo bajo, en contacto con el Páramo alto, aunque parece ir avanzando hacia el Sur, como se deduce de las obras de ampliación de los canales, que pueden observarse en distintos puntos de la comarca. Si observamos las puntuaciones y 
clasificaciones de estos dos tipos de paisajes, podemos deducir que la tendencia actual del paisaje en el Páramo es la evolución hacia paisajes de mayor puntuación; aunque si bien los paisajes de regadío obtienen una mayor puntuación debido a los atributos físicos, los paisajes de secano aumentan algo su puntuación por la aparición de recursos culturales como son las construcciones que todavía conservan las tipologías constructivas tradicionales, y que en el Páramoal to parecen haberse perdido por completo.

Pero no todos los cultivos de secano están evolucionando hacia cultivos de regadio, puede observarse también, sobre todo en el Sureste de la comarca, cultivos de secano, generalmente viñedos, actualmente abandonados y en parte invadidos por matorral. Éstos son los denominados paisajes de "secano degradado", clasificados como deficientes, y que por tanto son los que peor puntuación reciben en toda la comarca, por lo que la recuperación de estas zonas de cultivo, supondría un incremento de la calidad paisajística.

En el Norte de la comarca se encuentran los paisajes de "pastizal-matorral", que marcan el límite de la misma, hecho a tener en cuenta si se quiere delimitar la comarca del Páramo a partir de su caracterización paisajística.

Otros paisajes inducidos por la introducción del regadío son los canales y las choperas, que aparecen sobre todo en el Páramo alto. En el Páramo bajo también aparecen grandes choperas a lo largo de las márgenes del río Órbigo y sus afluentes.

Con una representación escasa, y fundamentalmente en el Páramo bajọ, se encuentran los encinares, que, aunque transformados en parte por la mano del hombre, representan los paisajes característicos de la zona menos alterados por él. Se trata de paisajes ricos y diversos, como queda reflejado en su puntuación, por lo que reciben una calificación de paisajes "muy buenos".

\section{LAS CONSTRUCCIONES Y EL PAISAJE}

\subsection{Tipología}

Antes de iniciar cualquier estudio sobre el impacto visual de las construcciones en el paisaje, se hace necesario establecer cuáles son las construcciones que pueden encontrarse, así como a qué tipología responden ${ }^{1}$.

De todas las construcciones encontradas en el área rural, se excluyeron las depuradoras de agua, los transformadores de corriente eléctrica, los cementerios y otras construcciones

${ }^{1}$ Para el establecimiento de la tipología constructiva del Páramo Leonés, se ha utilizado un estudio realizado en la Escuela Técnica Superior de Ingenieros Agrónomos de Lugo con el título "Estudio tipológico de las construcciones en el Páramo Leonés" Ángel Couto Yáñez, 1995, cuyas principales conclusiones quedan resumidas en el texto. cuyo análisis no es objeto de este estudio. Asimismo, quedan excluidas construcciones que estén dentro del casco urbano, sea cual sea la tipología a la que pertenezcan.

Las construcciones analizadas pueden clasificarse en tres grupos fundamentales:

\section{a-Construcciones agricolas}

Casetas agrícolas: son construcciones aisladas, de pequeño tamaño, cuya finalidad principal es guardar los aperos de labranza. Su planta es cuadrada, rectangular o circular y se desarrollan a una sola altura. La cubierta es a una o dos aguas y como material de cobertura se usa la teja curva o el fibrocemento. Suelen presentar aleros, pero no canalones o bajantes para el desagüe del agua de lluvia. Las paredes generalmente son vistas, de ladrillo, adobe o de tapial, pero en los casos en que están revocadas es con mortero de cemento o con barro. No suelen tener ventanas, por lo que la puerta, de madera o excepcionalmente de chapa galvanizada, se convierte en el único hueco presente.

Las fincas donde se encuentran enclavadas no siempre poseen cierre, pero si lo tienen es de alambre de espino o en malla, o de bloques de hormigón. Los accesos son de tierra.

Naves agrícolas: son de mayores dimensiones que las casetas y se usan para el almacenamiento de la cosecha y maquinaria, o como instalaciones ganaderas. El tipo básico es de planta rectangular, a una altura, con cubierta a dos aguas, y en menor grado a un agua, de placa ondulada de fibrocemento, pared vista de ladrillo, y en menor número debloque de hormigón o revocadas con mortero de cemento, y portalón de chapa galvanizada. No suelen existir canalones ni bajantes, pero cuando aparecen son de P.V.C. de color blanco.

En ocasiones existen construcciones auxiliares anejas, que pueden alcanzar dimensiones y características similares a la principal, llegando a tratarse de dos naves gemelas anexas. En algún caso se observan silos cónicos de acero adosados a ellas.

Gran parte de las fincas donde se ubican estas naves, presentan cierre. Éste suele ser de malla de alambre apoyada en postes metálicos o de alambre de espino, con una altura entre 0,8 y 1,5 metros. Los accesos suelen ser caminos de tierra o pistas sin asfaltar, aunque en algunos casos se trata de firme asfaltado.

\section{b - Establecimientos comerciales y naves industriales}

Se trata de industrias relacionadas con el sector agrícola o establecimientos pertenecientes al sector servicios Presentan gran variedad de formas, aunque normalmente éstas son rectangulares, con cubiertas a dos aguas 
realizadas con fibrocemento $\mathrm{y}$, en menor grado, con teja árabe o plana. Las paredes son de bloque de hormigón, y en algún caso de ladrillo, abundando los revoques de mortero de cemento, que suele pintarse de blanco. Los sistemas de recogida de agua no acostumbran a ser vistos, pero cuando lo son, canalones y bajantes se construyen de P.V.C. de color blanco

No suele tratarse de una sola nave, sino que llevan una o más naves anexas de igual o menor tamaño, e incluso grandes silos metálicos con forma cilíndrica.

La mayoría presenta rótulos comerciales pintados en los muros.

\section{c-Viviendas}

Se trata de construcciones unifamiliares, de edificación reciente $y$ es donde mayor variedad de formas se han observado. La finca presenta cierre de malla de alambre apoyada en postes metálicos, columnas de hormigón o ladrillo, unidas por rejas metálicas o de ladrillo macizo o de bloque de hormigón.

Las cubiertas son generalmente a dos aguas, de teja curva o plana y en algún caso aparece pizarra y sobre ellas se sitúan antenas y chimeneas. Siempre hay aleros sobre la línea de la fachada. Las paredes son de ladrillo visto o revocadas con mortero de cemento y en alguna ocasión con ladrillos vitrocerámicos, o con aplacadas de piedra natural pulida. Canalones y bajantes son de P.V.C., aunque a veces están ausentes.

Los accesos son pistas, asfaltadas o sin asfaltar, pero siempre en buen estado.

\subsection{Valoración del impacto visual de las construcciones agrarias en el paisaje}

Una vez establecida la tipología de las construcciones en la zona de estudio y, por tanto, sabiendo cuáles son las construcciones que se pueden encontrar en el medio rural del Páramo Leonés, se puede pasar a valorar el impacto visual que producen dichas construcciones en el paisaje.

A la hora de valorar el impacto de las construcciones antes mencionadas en el paisaje, es necesario establecer cuáles son las variables que intervienen en la integración de las construcciones en el paisaje. Para ello, se ha elaborado una lista de comprobación en la que se recogen las principales variables que intervienen. Para la confección de una lista de comprobación de estas características, es necesario realizar un estudio orientado en dos direcciones (Cañas I., 1995):

$1^{\circ}$.- Estudio bibliográfico en el que en una primera fase se analizan publicaciones extranjeras y nacionales y en una segunda fase se hace un estudio sobre la normativa española y más concretamente sobre la de los municipios de la zona (Normas Subsidiarias de Planeamiento Municipal de Ámbito Provincial de León).

En cuanto al estudio bibliográfico, se observa una cierta disparidad de criterios, mientras algunos autores se centran más en la pérdida de las tipologías tradicionales, otros exponen la preocupación por la proliferación de las nuevas construcciones, mientras que un menor porcentaje se centra en los parámetros que inciden en la integración, no coincidiendo todos los autores en señalar los mismos. En cambio, sí existen unos elementos comunes en la mayoría de los autores como son: la forma, la escala, el color, los materiales y los detalles (aleros, bajantes, canalones, puertas, huecos,...), y son éstos los que se tuvieron en cuenta, principalmente, en la realización del estudio.

Por otro lado, las principales variables señaladas por la normativa vigente son:

- $\mathbf{n}^{\circ}$ de plantas.

- inclinación de la cubierta.

- color de las fachadas.

- huecos en las fachadas.

- materiales de las fachadas.

- carpinterías de las fachadas.

- materiales de las cubiertas.

- color de las cubiertas.

- diseño de plantas.

- anuncios y carteles publicitarios exteriores.

- colocación de los contadores eléctricos en las fachadas.

$2^{\circ}$ Estudio piloto por la zona, que se realiza en dos etapas:

Recorrido piloto por toda la zona, a través de las carreteras y caminos que la atraviesan. Las variables más destacables que se observaron durante el primer recorrido por la zona, con relación a los recursos estéticos, fueron: la altura de los edificios, la forma de las cubiertas y el color. La textura, cuando se utilizan materiales brillantes es un factor distorsionador muy importante. Con relación a los condicionantes de posición de la instalación destacaban: interrupción de la línea del horizonte, tapar vistas y la fragmentación del espacio.

Estudio de fotografías aéreas de la zona. Del análisis de las fotografias aéreas pueden destacarse las siguientes variables:

* color de las cubiertas (destacando mucho los cambios).

* el color de la fachada unido al de la cubierta establece una analogía cromática con el paisaje.

* la inclinación de la cubierta y la forma a dos aguas.

* el color de la carpintería.

* la altura de los edificios y la agrupación de éstos. 
TABLA 4.1.

Lista de comprobación - impacto visual de las construcciones agrarias en el paisaje

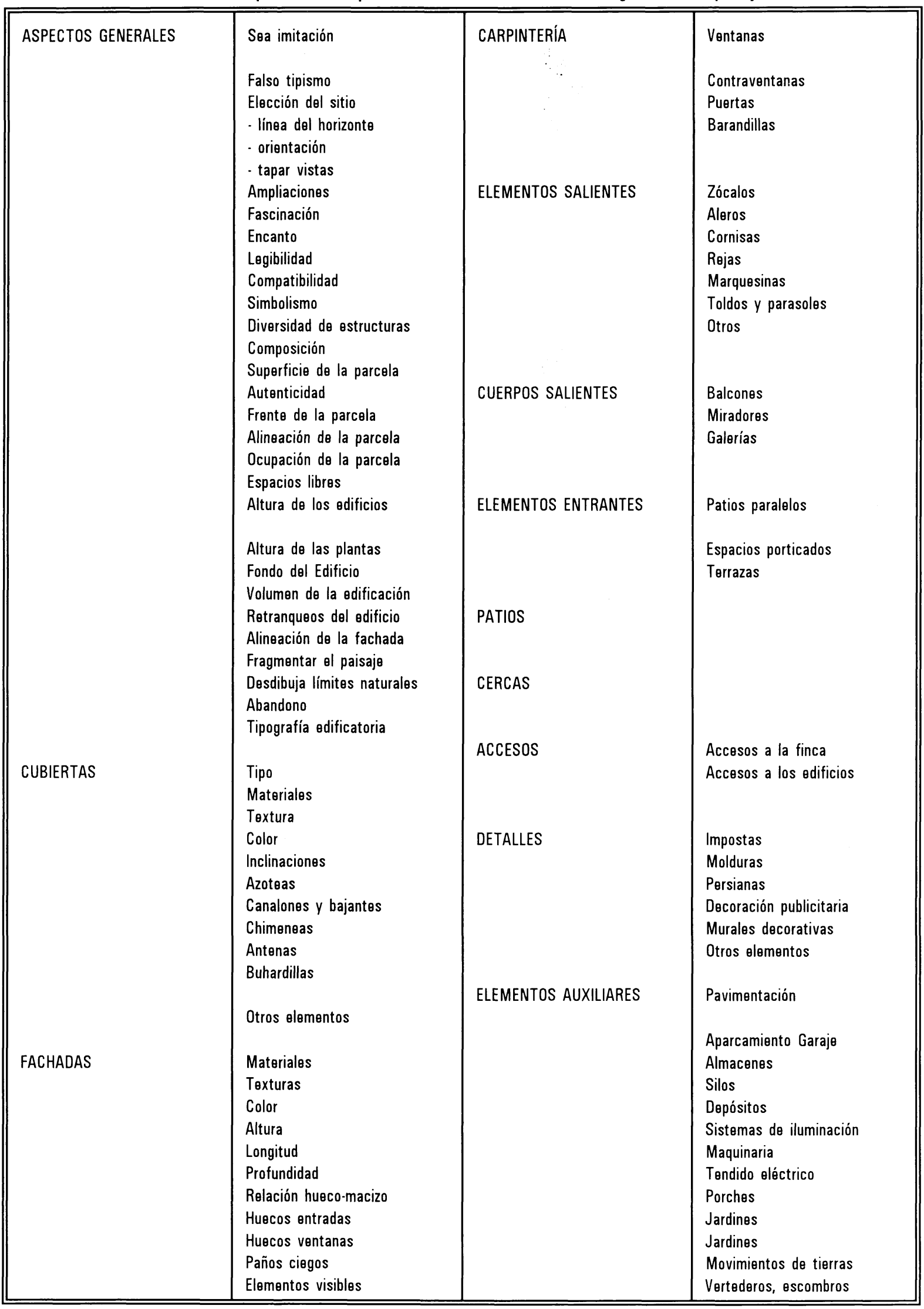


Una vez analizadas todas las variables desde el punto de vista de la bibliografía y de estudio del terreno, que pueden intervenir en el impacto de las construcciones agrarias, se puede construir una lista de comprobación (Tabla 4.1: lista de chequeo de las principales variables que intervienen en el impacto visual de las construcciones agrarias).

Para concretar en la zona de estudio aquellos elementos de las construcciones que pudieran influir sobre el paisaje, dicha lista de comprobación se materializó en tres fichas que se rellenan para cada una de las construcciones.

\subsection{Metodología de estudio}

Una vez conocidos los tipos más característicos de construcciones presentes en lazona de estudio, así como los elementos que intervienen en la integración de éstas en el paisaje, ya se puede pasar a estudiar el impacto visual que produce cada uno de los tipos constructivos en los diferentes paisajes en los que se encuentran situados.

Para ello se siguió la metodología de estudio que se describe a continuación:

$a$-En primer lugar se localizan las construcciones agrarias del medio rural de la zona. Con el apoyo de la fotografía aérea actual de la zona y de la cartografía existente, se localizan las construcciones sobre el terreno.

Posteriormente se visitan cada una de las construcciones localizadas. Una vez en las construcciones, se comprueba a qué tipo constructivo de los descritos en el apartado 4.1. pertenecen. Se fotografía la construcción y se procede a rellenar, para cada una, las fichas en las que se detalla su situación y todos aquellos elementos y variables de las mismas que pueden originar impacto sobre el paisaje en el que se encuentran.

Finalmente, y a partir de los datos proporcionados por las fichas de situación y tipología de las construcciones, cada construcción se puntúa de uno a cinco puntos, según su grado de adecuación al entorno, de acuerdo con la siguiente clasificación:

- Mala: 1 punto.

- Regular-mala: 2 puntos.

- Regular: 3 puntos.

- Regular-Buena: 4 puntos

- Buena: 5 puntos.

$b$ - Una vez obtenida la adecuación de la construcción se cruza con la valoración del paisaje en el que está situada, obteniéndose el impacto de la construcción en el paisaje, de acuerdo con la Tabla 4.2.

Como se deduce de dicha tabla, la clasificación global del impacto de las construcciones se establece mediante cinco grupos:

- Correcto: la construcción está perfectamente integrada con el paisaje.

- Admisible: aunque la construcción presenta algunos defectos, no tienen relevancia.

Tabla 4.2

Clasificación global de impacto de las construcciones en el paisaje, en función de la adaptación de la construcción al paisaje y de la valoración del mismo

\begin{tabular}{||l|l|l|l|l|l||}
\hline $\begin{array}{c}\text { ADECUACIÓN } \\
\text { PAISAJE }\end{array}$ & \multicolumn{1}{|c|}{ MALA } & \multicolumn{1}{|c||}{ REGULAR-MALA } & \multicolumn{1}{|c|}{ REGULAR } & BUENA-REGULAR & \multicolumn{1}{c||}{ BUENA } \\
\hline Degradado & Dudoso & Mejorable & Admisible & Correcto & Correcto \\
\hline Deficiente & Inadmisible & Dudoso & Admisible & Correcto & Correcto \\
\hline Mediocre & Inadmisible & Dudoso & Mejorable & Admisible & Correcto \\
\hline Bueno & Inadmisible & Inadmisible & Dudoso & Mejorable & Admisible \\
\hline Notable & Inadmisible & Inadmisible & Inadmisible & Dudoso & Mejorable \\
\hline Muy bueno & Inadmisible & Inadmisible & Inadmisible & Inadmisible & Mejorable \\
\hline Excelente & Inadmisible & Inadmisible & Inadmisible & Inadmisible & Dudoso \\
\hline
\end{tabular}


- Mejorable: la construcción afecta al paisaje, aunque no de forma importante.

- Dudoso: la construcción no está integrada con el entorno, sólo sería admisible si hay motivos importantes, como interés de tipo social.

- Inadmisible: la construcción afecta gravementeal paisaje.

En el apartado siguiente se detallan los resultados de la aplicación de la metodología descrita, en la zona de estudio.

\subsection{Valoración del impacto visual de las construcciones agrarias en la zona de estudio}

Se analizaron un total de 131 construcciones de las consideradas agrarias en la zona concreta del Páramo Leonés. Pudiendo establecerse como primera conclusión que todas las construcciones estudiadas se adaptan perfectamente a las tipologías descritas, excepto 4 de ellas correspondientes a palomares y otras 8 correspondientes a piscinas para cultivos. El resumen tipológico de las construcciones analizadas se detalla a continuación, mediante la Tabla 4.3 y el Gráfico 4.1 .

TABLA 4.3.

Tipologías constructivas

\begin{tabular}{||l|c||}
\hline \multicolumn{1}{|c|}{ TIPO DE CONSTRUCCIÓN } & $\mathbf{N}^{\mathbf{0}}$ \\
\hline CASETAS AGRÍCOLAS & 58 \\
\hline NAVES AGRÍCOLAS & 42 \\
\hline NAVES INDUSTRIALES & 20 \\
\hline PISCINAS & 8 \\
\hline PALOMARES & 4 \\
\hline TOTAL & $\mathbf{1 3 2}$ \\
\hline
\end{tabular}

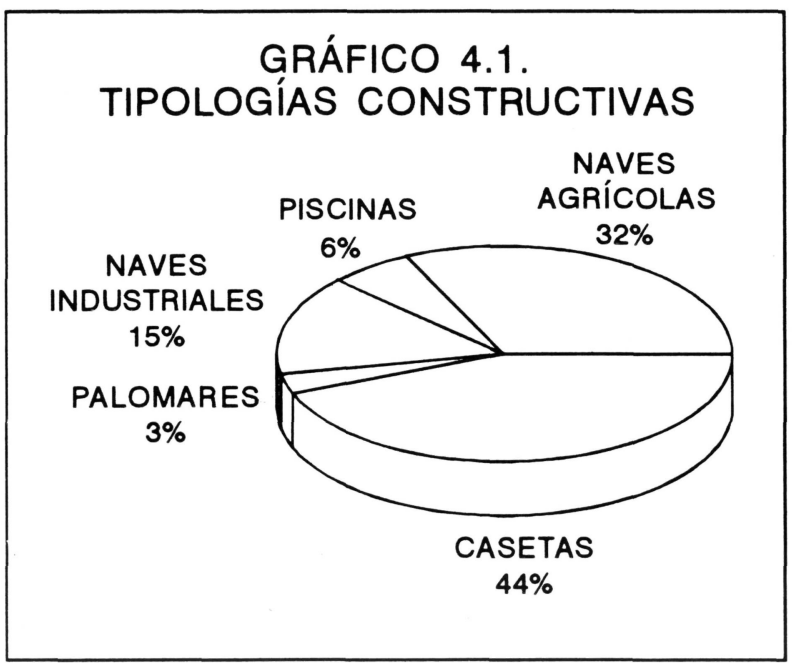

(c) Consejo Superior de Investigaciones Científicas Licencia Creative Commons 3.0 España (by-nc)
Como se mencionó en el apartado anterior, cada una de las construcciones se clasificaron según cinco tipos, correspondientes a los distintos grados de adecuación al paisaje: Mala, Regular-Mala, Regular, Regular-Buena y Buena. Los resultados globales de la adecuación de las construcciones son los siguientes (Tabla 4.4 y Gráfico 4.2):

\section{TABLA 4.4}

Grado de adecuación

\begin{tabular}{||l|l|}
\hline \multicolumn{1}{|c|}{ GRADO DE ADECUACIÓN } & $\mathbf{N}^{\mathbf{0}}$ \\
\hline MALA & 70 \\
\hline REGULAR-MALA & 28 \\
\hline REGULAR & 16 \\
\hline REGULAR-BUENA & 7 \\
\hline BUENA & 10 \\
\hline
\end{tabular}

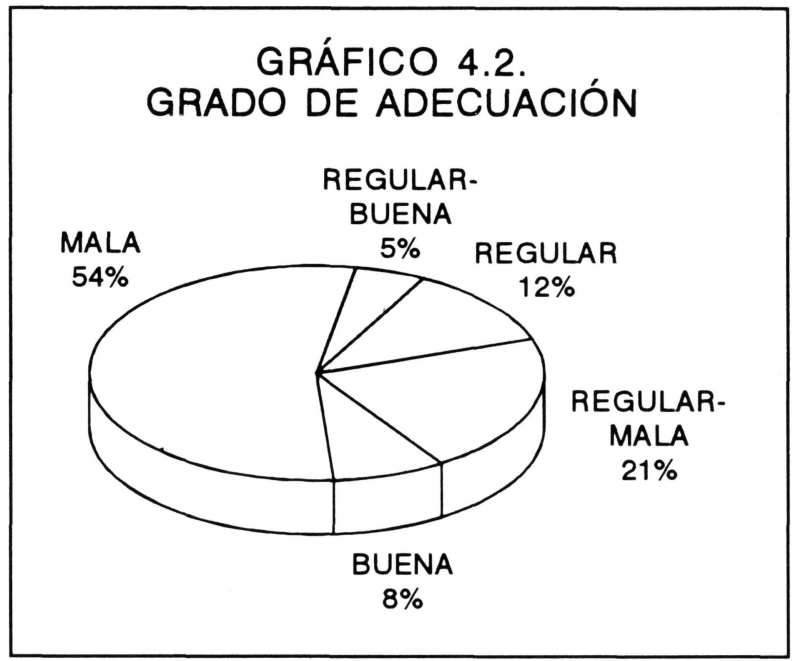

Casetas agrícolas:

A partir del grado de adecuación y del paisaje en el que se encuentra cada una de las construcciones, se establece la

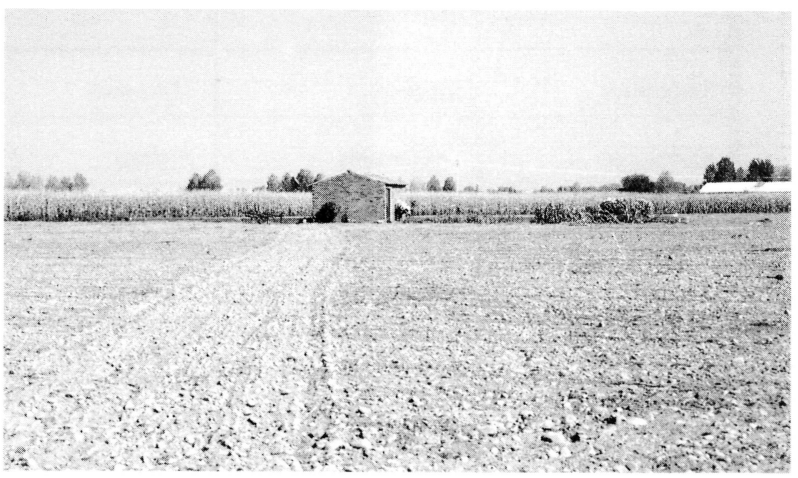

Caseta agrícola sobre paisaje "mosaico de cultivos de regadio y secano". Grado de adecuación: dudosa.

http://informesdelaconstruccion.revistas.csic.es 
clasificación global de impacto visual, de acuerdo con la Tabla 4.2, expuesta en el apartado anterior. Los resultados se exponen a continuación, mediante la Tabla 4.5 .

En el Gráfico 4.3. se resume la clasificación global del impacto visual de las construcciones agrarias.

TABLA 4.5 .

Casetas agrícolas

\begin{tabular}{||l|l|r|l||}
\hline $\begin{array}{c}\text { GRADO DE } \\
\text { ADECUACIÓN }\end{array}$ & \multicolumn{1}{|c|}{ PAISAJE } & $\mathbf{N}^{\circ}$ & \multicolumn{1}{c||}{$\begin{array}{c}\text { CLASIFICACIÓN } \\
\text { GLOBAL }\end{array}$} \\
\hline Mala & Regadio intensivo & 3 & Inadmisible \\
\hline Mala & Mosaico regadío & 3 & Inadmisible \\
\hline Mala & Chopera & 1 & Inadmisible \\
\hline Mala & Secano & 10 & Inadmisible \\
\hline Regular-Mala & Pastizal & 1 & Dudosa \\
\hline Regular-Mala & Secano & 10 & Dudosa \\
\hline Regular-Mala & Mosaico regadío & 6 & Inadmisible \\
\hline Regular-Mala & Regadío-secano & 1 & Dudosa \\
\hline Regular & Regadío intensivo & 3 & Dudosá \\
\hline Regular & Mosaico-Regadío & 2 & Dudosa \\
\hline Regular & Regadío-secano & 1 & Mejorable \\
\hline Regular & Secano & 5 & Mejorable \\
\hline Regular & Chopera & 1 & Inadmisible \\
\hline Regular-Buena & Secano & 3 & Admisible \\
\hline Regular-Buena & Mosaico regadío & 1 & Mejorable \\
\hline Buena & Mosaico regadío & 1 & Admisible \\
\hline Buena & Correcta \\
\hline Buena & Rdmisible \\
\hline
\end{tabular}

GRÁFICO 4.3 . CASETAS AGRÍCOLAS

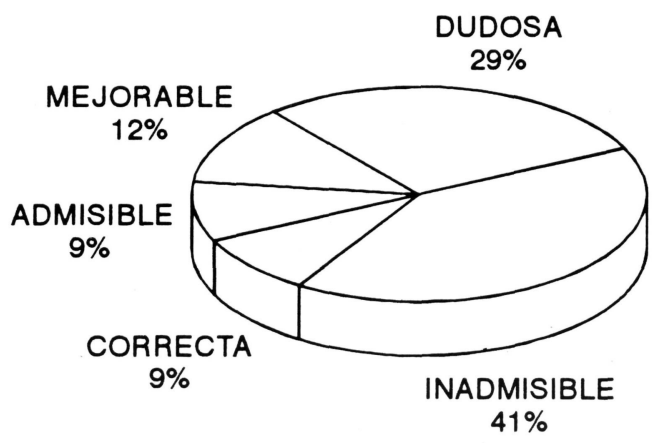

(c) Consejo Superior de Investigaciones Científicas Licencia Creative Commons 3.0 España (by-nc)
Naves agrícolas:

El impactovisual de las naves agrícolas se resume mediante la Tabla 4.6 y el Gráfico 4.4 .

TABLA 4.6.

Naves agrícolas

\begin{tabular}{||l|l|r|l||}
\hline \multicolumn{1}{|c|}{$\begin{array}{c}\text { GRADO DE } \\
\text { ADECUACIÓN }\end{array}$} & \multicolumn{1}{|c|}{ PAISAJE } & N $^{\circ}$ & \multicolumn{1}{c|}{$\begin{array}{c}\text { CLASIFICACIÓN } \\
\text { GLOBAL }\end{array}$} \\
\hline Mala & Regadio intensivo & 13 & Inadmisible \\
\hline Mala & Pastizal & 3 & Inadmisible \\
\hline Mala & Mosaico regadio & 7 & Inadmisible \\
\hline Mala & Secano & 5 & Inadmisible \\
\hline Regular-Mala & Regadio intensivo & 2 & Inadmisible \\
\hline Regular-Mala & Regadio intensivo & 2 & Inadmisible \\
\hline Regular-Mala & Secano & 3 & Dudosa \\
\hline Regular & Mosaico regadio & 2 & Dudosa \\
\hline Regular & Secano & 1 & Mejorable \\
\hline Regular & Regadio intensivo & 2 & Dudosa \\
\hline Regular-Buena & Regadío intensivo & 1 & Mejorable \\
\hline Regular-Buena & Pastizal & 1 & Admisible \\
\hline \hline
\end{tabular}

GRÁFICO 4.4 . NAVES AGRÍCOLAS
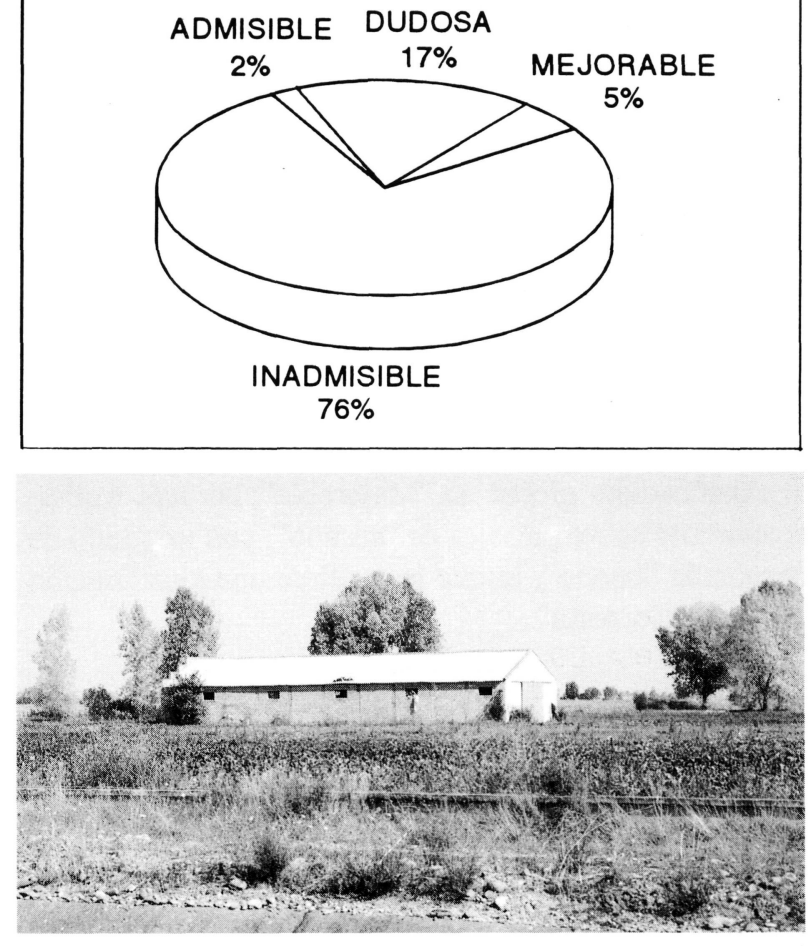

Nave agrícola sobre paisaje "mosaico de cultivos de regadio". Grado de adecuación: inadmisible.

http://informesdelaconstruccion.revistas.csic.es 


\section{Naves industriales:}

En este apartado se han analizado 20 naves industriales. Éstas siempre se encontraron situadas en las cercanías de las poblaciones de mayor desarrollo económico, en diversos paisajes, pero todas ellas se clasificaron como malas, en cuanto al grado de adaptación al paisaje se refiere. Por lo tanto, todas ellas son inadmisibles, independientemente del paisaje en el que se encuentren.

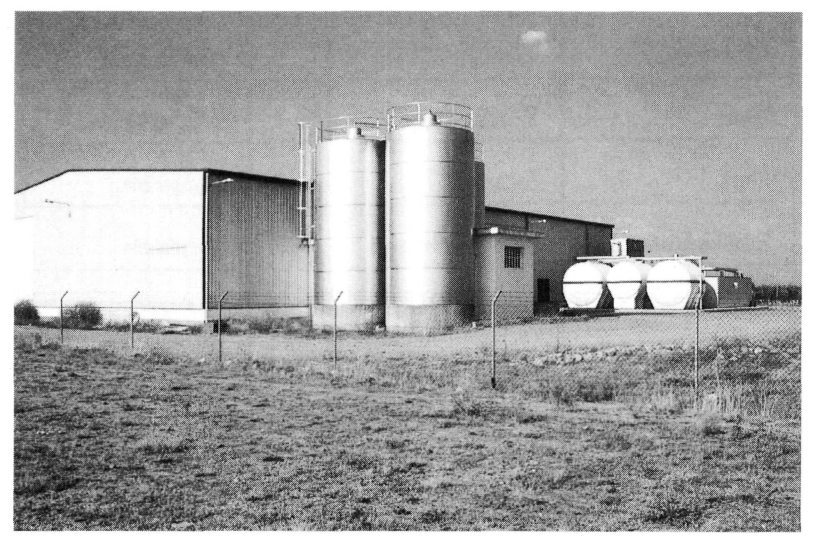

Nave industrial sobre paisaje "secano". Grado de adecuación: inadmisible.

\section{Palomares:}

Como se indicó al principio del presente apartado, este tipo de construcciones no aparecen reflejadas en el estudio tipológico correspondiente a la comarca.

Se trata de construcciones de planta redonda o cuadrada. Los muros son de ladrillo revocados con mortero de cal blanco o de adobe. Las cubiertas se desarrollan a dos alturas y están construidas con teja árabe, sin presentar ningún elemento destacable. Los palomares realizados con adobe conservan las tipologías constructivas típicas de la comarca del Páramo Leonés.

En total aparecen 4 de estas construcciones, de las que una presenta un grado de adecuación "regular-bueno", sobre un paisaje de "mosaico de cultivos en regadío", por lo que su clasificación global es "Mejorable"; las tres restantes aparecen sobre paisajes de "secano", con un grado de adecuación "bueno", lo que le confiere una clasificación global de "Correcta".

\section{Piscinas:}

Al igual que los palomares, las piscinas no aparecen reflejadas en el estudio tipológico correspondiente a la comarca. Se trata de construcciones de planta redonda en todos los casos, con un diámetro aproximado de unos $8 \mathrm{~m}$ y una altura aproximada de $2,5 \mathrm{~m}$. Por tanto, son todas muy similares en cuanto a forma, encontrándose las diferencias fundamentales en la pintura que reviste las paredes, lo que inducirá las diferencias fundamentales en cuanto a su adecuación al paisaje. De esta forma, cinco de las ocho piscinas aparecen con sus paredes pintadas, en todos los casos de color verde, presentando un grado de adecuación "malo", que por estar en paisajes "mosaico de regadío y secano", resultan ser "Inadmisibles"; mientras que las tres piscinas restantes, que tienen sus paredes sin pintar, presentan una adecuación "regular-mala" y resultan "Dudosas".

\subsection{Conclusiones}

La principal conclusión que puede destacarse es que el paisaje del Páramo Leonés es un paisaje marcado por la intervención del hombre, como puede deducirse de la gran cantidad de construcciones que aparecen esparcidas por todo el espacio agrario de la comarca.

El grado general de las construcciones que aparecen en los diferentes paisajes de la comarca es muy escaso, siendo "Malo" en la mayor parte de los casos. Por tanto, una gran parte de las construcciones reciben una clasificación global de impacto de "Inadmisible", es decir, que afectan de forma grave al paisaje.

El resto de los casos se reparte de forma similar entre "Dudoso" (la construcción no está integrada con el entorno y sólo sería admisible si hay motivos importantes) y "Mejorable" (la construcción afecta al paisaje aunque no de forma importante).

En pocos casos la integración de las construcciones reciben la clasificación de "Admisible" (aunque la construcción presenta algunos defectos, no tienen relevancia) y en menos aún se clasifican como "Correcta" (la construcción está perfectamente integrada con el paisaje).

Los tipos constructivos que mejor se integran en el paisaje son las casetas agrícolas. Las naves agrícolas, en general, se adaptan de forma muy escasa al paisaje, recibiendo en casi un $80 \%$ de los casos la calificación de "Inadmisibles". En el caso de las naves industriales, su adaptación es siempre "Inadmisible". Las piscinas no presentan una gran variedad de forma, y su adaptación al paisaje varía entre "Inadmisibles" y "Dudosas", en función de la pintura de sus muros. Como excepción se encuentran los palomares, que en la mayoría de los casos presentan una adecuación al paisaje correcta, debido fundamentalmente a la conservación de los elementos constructivos tradicionales, que no sólo se integran con el paisaje, sino que en muchas ocasiones lo mejoran.

Si analizamos cuáles son los elementos de las diferentes construcciones que más inciden sobre el paisaje, cabe destacar que la introducción de nuevos materiales de 
construcción es uno de los aspectos fundamentales que han incidido en la falta de adecuación de las edificaciones a su entorno. Se trata de materiales que permiten el alzamiento de cualquier edificación en un intervalo de tiempo muy reducido, pero sus colores y texturas contrastan de forma patente con el paisaje en el que se pretenden integrar, que, por lo general, se trata de un paisaje rural y agrícola.

Las construcciones que con más asiduidad utilizan los nuevos materiales son las naves industriales. Fibrocemento, chapa galvanizada, bloque de hormigón,..., son materiales habituales en este tipo de construcciones, mientras que los materiales tradicionales sólo pueden encontrarse actualmente en las casetas y palomares.

El color de las construcciones es otro de los elementos a tener en cuenta a la hora de juzgar la integración en el paisaje. Colores llamativos influyen de manera decisiva en la calificación negativa obtenida por la construcción, así como en su adecuación al paisaje que le rodea. Por contra, los colores aterrados mejoran la integración en paisajes de secano, aunque en ocasiones el contraste de tonos entre paisaje y construcción enriquece al primero y embellece a la segunda.

Las texturas brillantes provocan un efecto visible desde grandes distancias, que contrasta con las texturas circundantes provocando un impacto inadmisible en el paisaje. Este efecto se detecta fundamentalmente en portones, cubiertas y silos asociados a naves agrícolas e industriales.

El tamaño de la construcción, en particular la altura, influye de manera importante. Así las construcciones de grandes dimensiones, naves agrícolas e industriales, se integran con dificultad en el paisaje. Una altura elevada genera un fraccionamiento del horizonte, tapa vistas, etc, ..., ocasionando, una vez más, un impacto inadmisible en el paisaje

En definitiva, se puede concluir que las construcciones actuales en el Páramo Leonés afectan de forma importante al paisaje. Una vez analizados los elementos constructivos de todas las construcciones estudiadas, puede deducirse que esta falta de adaptación al paisaje es consecuencia, fundamentalmente, de la pérdida de la arquitectura popular de toda la comarca

La arquitectura rural está muy unidaa la situación económica de la región. Así, la arquitectura popular del Páramo leonés se encuentra en claro retroceso en toda la región y de forma especial en el Páramo alto. Las pocas muestras de arquitectura tradicional que aún pueden observarse en la zona, aparecen fundamentalmente en el Páramo bajo, especialmente en aquellos municipios económicamente menos desarrollados, incluso sobre paisajes abandonados y degradados (aunque en estos últimos casos en mal estado de conservación)
La desaparición de las construcciones tradicionales y la pérdida de carácter de las construcciones modernas se puede atribuir a tres factores fundamentales: las construcciones hechas con materiales tradicionales, como la tierra, precisan de la acción preservadora del hombre en mucha mayor medidaque otras hechas con otros materiales, el aumento de la renta "per cápita" de la población rural ha contribuido a acelerar el proceso de invasión de nuevos materiales y técnicas constructivas y, por último, con la aparición de las nuevas construcciones, la transmisión oral de las técnicas tradicionales se va perdiendo.

\section{BIBLIOGRAFÍA}

ALONSO PONGA, J.L.; 1994: "La arquitectura del barro". Junta de Castilla y León. Consejeria de Cultura y Turismo.

AYUGATELLEZ,F.; 1991: "Evolucióndelaedificaciónagraria en España. Su incidencia en el paisaje natural". Publicación: Informes de la Construcción. 43 (416): 39-52.

BELL, S.; 1993: "Elements of vissual desing in the landscape".

BERTUCCI, R. Y RIPPO, G. D'A: “Rilievo e mappatua dell impatto visivo mel paesaggio". Inst. Universitario di Andritettura de Venezia. Dpto. di scienza e tecnica del restammo.

B.O.P. 13 de julio. "Normas subsidiarias de planeamiento municipal de ámbito provincial de León".

CABRERO DIÉGUEZ, V. et al.; 1989: "La provincia de Leóny sus comarcas. Capitulo no 17. El Páramo Leonés". Diario de León.

CAÑAS GUERRERO, I.; 1992: “Integración de las construcciones agrarias en el paisaje: el color". Tesis doctoral. Universidad Politécnica de Madrid. Sin publicar.

CAÑAS GUERRERO, I; TEIJEIRO RODRIGUEZ, T; ORTIZ SANZ, J.; 1994: "Método mixto de estimación del impacto paisajístico de la construcción".

CENSO DE POBLACIÓN Y VIVIENDA.; 1991: "Nomenclator de las ciudades, Villas, Lugares, aldeas y demás entidades de la población, con especificación de sus núcleos".

CONFEDERACIÓN HIDROGRÁFICA DEL DUERO: "Mapas de la red de canales y acequias".

CORTIZO ÁlVAREZ, J.; 1989: "Los asentamientos en la provincia de León: comercio, servicios y jerarquía funcional". Universidad de León. Servicio de Publicaciones.

DÍEZ ANITA, S.; 1993: "Los palomares en la provincia de León". Caja de España.

DÍEZ GONZÁLEZ, F. A.; 1984: “Comarcas de León en la España comarcal”. Diputación Provincial de León. 
DÍEZ HERRERO, A.; 1992: "IV jornadas sobre el paisaje. Alternativas de desarrolloy conservación del paisaje". Segovia.

DIPUTACIÓN PROVINCIAL DE LEÓN; 1994: “La población de León. Evolución en el siglo XX”. Gabinete de Planificación.

DIPUTACIÓN PROVINCIAL DELEÓN; “Mapa dela provincia de León. E: 1:250.000"

ESPINOZA, G. et al.; 1994: "Manual de evaluación de impacto ambiental. Conceptos y antecedentes básicos". Comisión Nacional de Medio Ambiente (CONAMA). Chile.

FRANCOPELLITERO,D.; 1986: "Transformaciones del espacio agrario en el Páramo de León”. Institución Fray Bernardino Sahagún de la Excma. Diputación Provincial de León.

GARCÍA GRINDE, J.L.; 1991: "La arquitectura popular leonesa" Tomos I y II. Excelentísima Diputación Provincial de León

GÓMEZ OREA, DOMINGO.; 1988: "Evaluación del impacto ambiental de proyectos agrarios". Secretaria General Técnica Ministerio de Agricultura, Pesca y Alimentación, Madrid.

HERNÁNDEZ MOR, M.; 1995: "Valoración del paisaje y del impacto visual de las construcciones agrarias en el Páramo Leonés (Páramo alto)". Trabajo fin de carrera, E.T.S.I. de Montes. Universidad Politécnica de Madrid.

INSTITUTO GEOGRÁFICO NACIONAL: "Mapa provincial de León. E: 1:200.000"

\section{INSTITUTO TECNOLÓGICO Y GEOMINERO DE ESPAÑA:}

"Mapa geológico de la provincia de León. E: 1:200.000".

JUNTA DE CASTILLA Y LEÓN; 1994: “Datos estadísticos de los municipios de Castilla y León".

JUNTA DE CASTILLA Y LEÓN; 1990: "Geografia de Castilla $y$ León $n^{o}$ 3. Los espacios naturales". Ed. Ámbito s.a. Valladolid.

JUNTA DE CASTILLA Y LEÓN; 1990: "Geografía de Castilla y León $n^{\circ}$ 8. Las comarcas tradicionales". Ed. Ámbito s.a. Valladolid.

M.A.P.A.; 1977: “Agroclimatología de España”. Cuaderno nº 7. Madrid.
M.A.P.A.: "Mapa de cultivos y aprovechamientos. E: 1:50.000. Hojas $n^{\circ} 160,161,193,194,231,232,270 "$ ".

MARTÍN DUQUE, J.F.; 1992: “Actas de las Vjornadas sobre el paisaje". Segovia.

MINISTERIO DE CULTURA; 1991: "Jornadas sobre conservación y restauración de monumentos". Madrid 24 y 25 de abril de 1989. Ministerio de Cultura. Madrid.

M.O.P.T.; 1992: "Bases para el diseño y construcción con tapial".

MORADO, G.; 1991: "Impacto enla ingeniería rural". Seminario sobre la evaluación del impacto ambiental. Colegio Oficial de Ingenieros Agrónomos de Asturias".

NOVOA CORREA, J. C.; 1995: "Valoración del paisaje y del impacto visual de las construcciones agrarias en el Páramo Leonés (Páramo bajo)". Trabajo fin de carrera, E.T.S.I. de Montes. Universidad Politécnica de Madrid.

PASTRANA, L.: "El Páramo, introducción histórica". Ed. leonesas.

PONÉZAR, M.; 1992: “Impacto ambiental en proyectos agrícolas. Problemas especificos".

PURCELL, A.T.; 1992: “Abstract and specific physical attributes and the experience of landscape". Publicacion: Journal of environmental management. 34,3 .

RASMUSSEN , W.; 1993: "Visual space index". Publicación: Journal of environmental management. 38

SÁNCHEZ BADIOLA, J.J.; 1991: "El fenómeno comarcal en la provincia de León". Diputación Provincial de León.

SERVICIO CARTOGRÁFICO DEL EJÉRCITO: "Mapas topográficos $n^{\circ} 160,161,193,194,231,232,270$. E: 1:50.000".

SMARDON, R. C. Y KARP, J.P.: “The legal landscape". Van Nostrand Reinhold, New york.

UNIVERSIDAD HISPANOAMERICANA DE SANTA MARÍA DE LA RÁBIDA; 1992: "Valoración del impacto ambiental. Procedimientos y técnicas". 